\title{
Polycyclic Guanidine Alkaloids from Poecilosclerida Marine Sponges
}

\author{
Estelle Sfecci ${ }^{1}$, Thierry Lacour ${ }^{2}$, Philippe Amade ${ }^{1}$ and Mohamed Mehiri ${ }^{1, *}$ \\ 1 Nice Institute of Chemistry, Marine Natural Product Team, University Nice Sophia Antipolis, Parc Valrose, \\ 28 avenue de Valrose, 06108 Nice Cedex 02, France; sfecci@unice.fr (E.S.); amade@unice.fr (P.A.) \\ 2 Biopreserv, 4 traverse Dupont, 06130 Grasse, France; tlacour@biopreserv.fr \\ * Correspondence: mehiri@unice.fr; Tel.: +33-492-076-154 \\ Academic Editor: Kirsten Benkendorff
}

Received: 2 February 2016; Accepted: 1 April 2016; Published: 9 April 2016

\begin{abstract}
Sessile marine sponges provide an abundance of unique and diversified scaffolds. In particular, marine guanidine alkaloids display a very wide range of biological applications. A large number of cyclic guanidine alkaloids, including crambines, crambescins, crambescidins, batzelladines or netamins have been isolated from Poecilosclerida marine sponges. In this review, we will explore the chemodiversity of tri- and pentacyclic guanidine alkaloids. NMR and MS data tools will also be provided, and an overview of the wide range of bioactivities of crambescidins and batzelladines derivatives will be given.
\end{abstract}

Keywords: marine sponges; Poecilosclerida; alkaloids; crambescidins; batzelladines; analytical tools; bioactivity

\section{Introduction}

The most primitive benthic marine organisms are also among the most chemodiversified producers of secondary metabolites (SM). These compounds are used for predation and competition for space, as well as for communication, and protection against potential surrounding aggressors. Due to the high water dilution, the produced metabolites exhibit several potent biological activities [1]. Several reviews dealing with bioactive marine natural products, in particular, alkaloids have been published in the last few decades [2-19]. Of the many different marine species that have been researched, sponges are likely to be the most studied sources of marine natural products due to the large amount of structurally diverse SM scaffolds they produce. Even so, the last few years have seen a slight decline in the number of newly described metabolites [17,18].

In this review, we focused on the chemodiversity and biological activities of batzelladine- and crambescidin-like guanidine alkaloids isolated from Poecilosclerida marine sponges. These polycyclic guanidine alkaloids are extremely versatile SM [20]. Since their original isolation in 1989, several revisions have been made and many aspects remain to be studied. However, what is clear is that they seem to be specific to Poecilosclerida marine sponges. Over 53 derivatives have been isolated and their original structures, based on chemical degradation studies and extensive NMR and MS studies, have been revised since the development of their total synthesis. The structural and stereochemical complexity of this class of natural products have inspired the development of a number of new synthetic methodologies [21-34], which in turn has led to several total syntheses [31,33,35-50] beyond the scope of this review. Finally, these unique and fascinating structures are coupled with a wide range of biological activities due to the typical shape of their tricyclic skeleton. However, little is known about their exact mechanism of action. 


\section{Structural Diversity}

From 1989 to 2015, 53 TGA (triazaacenaphthylene guanidine alkaloids) have been isolated. Natural TGA reported to date are listed in Tables 1 and 2.

Ptilomycalin A (1), isolated from the sponges Ptilocaulis spiculifer and Hemimycale sp. [51], is the parent member of a group of related metabolites. This includes crambescidins [52-55] and their derivatives (isocrambescidine (6) [52,56], crambidine (7) [52], neofolitispates (8-10) [57], crambescidin acid (14) [58], crambescidic acid (15) [59], ptilomycalin D (17) [60], monanchocidins (18-22) [61,62], and monanchomycalins (23-25) [63,64]), which are found in several sponges (Crambe crambe, Neofolitispa dianchora, Monanchora arbuscula, Monanchora ungiculata, Monanchora dianchora, and Monanchora pulchra), as well as, for a subset, in the New Caledonian starfishes Fromia monilis and Celerina heffernani (Table 1) [65]. Additional guanidine derivatives have been isolated, such as the batzelladines A-E (26-30) from the Bahamanian sponge Batzella sp. (which has since been revised to Crambe crambe) [66], batzelladines F-I (31-34) from the Jamaican sponge Batzella sp. [67], batzelladine J (51) from the Caribbean sponge Monanchora unguifera [59], and their derivatives (clathriadic acid (41) [68], merobatzelladines (42,43) [69], and batzellamide A (50) [70]) from Monanchora unguifera, Clathria calla, and Monanchora arbuscula (Table 2).

TGA are only found in Poecilosclerida marine sponges. To date, they have been only isolated from the Crambidae (Crambe, Monanchora), Mycalidae (Arenochalina, Mycale), Phoriospongidae (Batzella, Hemimycale), and Microcionidae (Clathria) families [71]. Sponges that produce TGA can be found in warm waters, without distinction between oceans and seas. A large majority were sampled in the Caribbean Sea (Figure 1).

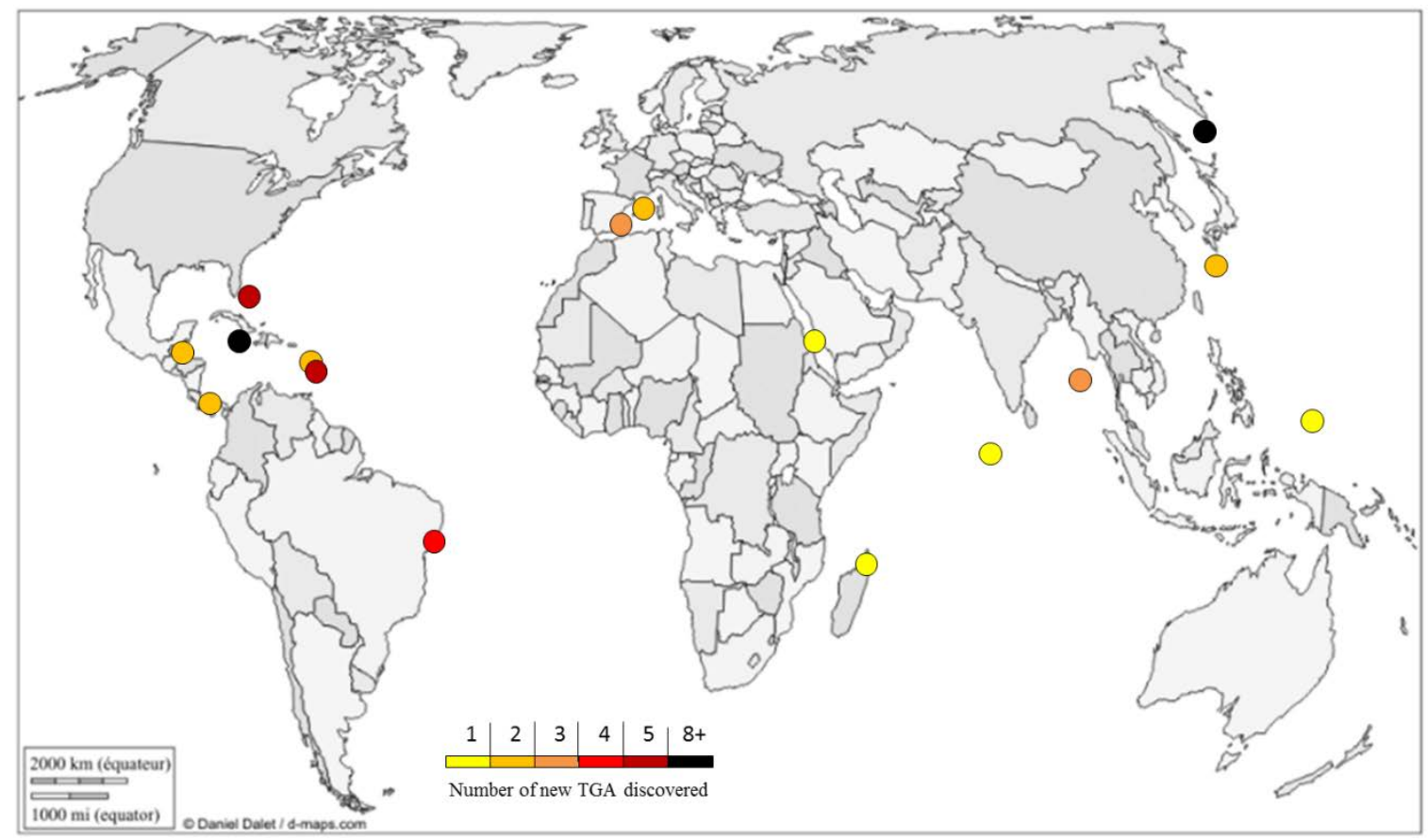

Figure 1. Geographical repartition of new TGA (triazaacenaphthylene guanidine alkaloids) discovered from 1989 to 2015 . Graphic ${ }^{\circledR}$ d-maps.com [72]. Used with permission. 
Table 1. Reviewed crambescidin-like GA (guanidine alkaloids) from 1989 to 2015.

\begin{tabular}{|c|c|c|c|c|c|c|c|}
\hline Metabolite & Species & Sampling Site & $\begin{array}{l}\text { Discovery } \\
\text { Year }\end{array}$ & $\begin{array}{l}\text { Guanidine } \\
\text { Moiety }\end{array}$ & $\begin{array}{l}\text { Biological } \\
\text { Activity }\end{array}$ & $\begin{array}{l}\text { Synthesis } \\
\text { Described }\end{array}$ & Ref. \\
\hline ptilomycalin A (1) & $\begin{array}{l}\text { Hemimycale sp. Ptilocaulis } \\
\text { spiculifer }\end{array}$ & Red sea & 1989 & 1 & $\mathrm{Av}, \mathrm{Am}, \mathrm{At}$ & Yes & {$[42,51,73]$} \\
\hline crambescidin 800 (2) & Crambe crambe & Palma de Mallorca, Mediterranean sea & 1991 & 1 & $\mathrm{Av}, \mathrm{Am}, \mathrm{At}$ & Yes & {$[54-56,73,74]$} \\
\hline crambescidin 816 (3) & Crambe crambe & Palma de Mallorca, Mediterranean sea & 1991 & 1 & $\begin{array}{l}\mathrm{Av}, \mathrm{At}, \mathrm{Ca}^{2+} \\
\text { antagonist }\end{array}$ & No & {$[52,55,56,75]$} \\
\hline crambescidin $830(4)$ & Crambe crambe & Palma de Mallorca, Mediterranean sea & 1991 & 1 & n.t. & No & [55] \\
\hline crambescidin 844 (5) & Crambe crambe & Palma de Mallorca, Mediterranean sea & 1991 & 1 & $\mathrm{Av}$ & No & {$[55,56]$} \\
\hline 13,14,15-isocrambescidine 800 (6) & Crambe crambe & Banyuls, Mediterranean sea & 1993 & 1 & Not active & Yes & {$[36,42,56]$} \\
\hline crambidine $(7)$ & Crambe crambe & Banyuls, Mediterranean sea & 1993 & 1 & n.t. & Yes & {$[45,49,52]$} \\
\hline neofolitispate 1 (8) & Neofolitispa dianchora & Andaman Islands, Indian Ocean & 1999 & 1 & $\mathrm{Av}$ & No & [57] \\
\hline neofolitispate 2 (9) & Neofolitispa dianchora & Andaman Islands, Indian Ocean & 1999 & 1 & $\mathrm{Av}$ & Yes & [57] \\
\hline neofolitispate $3(\mathbf{1 0})$ & Neofolitispa dianchora & Andaman Islands, Indian Ocean & 1999 & 1 & $\mathrm{Av}$ & No & [57] \\
\hline crambescidin 359 (11) & Monanchora ungiculata & Belize, North Atlantic Ocean & 2000 & 1 & n.t. & Yes & {$[33,41,48,53]$} \\
\hline crambescidin 431 (12) & Monanchora ungiculata & Belize, North Atlantic Ocean & 2000 & 1 & n.t. & No & [53] \\
\hline crambescidin 826 (13) & Monanchora sp. & Palau, Pacific Ocean & 2003 & 1 & $\mathrm{Av}$ & No & [54] \\
\hline crambescidin acid (14) & Monanchora ungiculata & Maldive Islands, Indian Ocean & 2004 & 1 & At & No & [58] \\
\hline crambescidic acid (15) & $\begin{array}{l}\text { Monanchora unguifera } \\
\text { Monanchora dianchora }\end{array}$ & Panama, Caribbean side, Atlantic Ocean & 2005 & 1 & n.t. & No & [59] \\
\hline 16ß-hydroxycrambescidin 359 (16) & Monanchora unguifera & Jamaica, North Atlantic Ocean & 2007 & 1 & $\mathrm{Am}$ & No & [73] \\
\hline ptilomycalin D (17) & Monanchora dianchora & Madagascar, Indian Ocean & 2007 & 1 & n.t. & No & [60] \\
\hline monanchocidin A (18) & Monanchora pulchra & Urup Island, North Pacific Ocean & 2010 & 1 & At & No & [61] \\
\hline monanchocidin B (19) & Monanchora pulchra & Urup Island, North Pacific Ocean & 2011 & 1 & At & No & [62] \\
\hline monanchocidin C (20) & Monanchora pulchra & Urup Island, North Pacific Ocean & 2011 & 1 & At & No & [62] \\
\hline monanchocidin D (21) & Monanchora pulchra & Urup Island, North Pacific Ocean & 2011 & 1 & At & No & [62] \\
\hline monanchocidin E (22) & Monanchora pulchra & Urup Island, North Pacific Ocean & 2011 & 1 & At & No & [62] \\
\hline monanchomycalin A (23) & Monanchora pulchra & Urup Island, North Pacific Ocean & 2012 & 1 & At & No & [63] \\
\hline monanchomycalin B (24) & Monanchora pulchra & Urup Island, North Pacific Ocean & 2012 & 1 & n.t. & No & [63] \\
\hline monanchomycalin C (25) & Monanchora pulchra & Urup Island, North Pacific Ocean & 2013 & 1 & n.t. & No & [64] \\
\hline
\end{tabular}

Am, antimicrobial activity; Av, antiviral activity; At, antitumoral activity; and n.t., not tested. 
Table 2. Reviewed batzelladine-like GA from 1989 to 2015.

\begin{tabular}{|c|c|c|c|c|c|c|c|}
\hline Metabolites & Species & Sampling Site & $\begin{array}{c}\text { Discovery } \\
\text { Year }\end{array}$ & $\begin{array}{l}\text { Guanidine } \\
\text { Moiety }\end{array}$ & $\begin{array}{l}\text { Biological } \\
\text { Activities }\end{array}$ & $\begin{array}{l}\text { Synthesis } \\
\text { Described }\end{array}$ & Ref. \\
\hline batzelladine A (26) & Batzella sp. & Bahamas, North Atlantic Ocean & 1996 & 3 & $\mathrm{Am}, \mathrm{Av}$ & Yes & {$[32,46,66]$} \\
\hline batzelladine B (27) & Batzella sp. & Bahamas, North Atlantic Ocean & 1996 & 3 & Av & No & [66] \\
\hline batzelladine C (28) & Batzella sp. & Bahamas, North Atlantic Ocean & 1996 & 2 & $\mathrm{Av}, \mathrm{Am}, \mathrm{At}$ & No & {$[66,73]$} \\
\hline batzelladine D (29) & Batzella sp. & Bahamas, North Atlantic Ocean & 1996 & 2 & $\mathrm{Av}, \mathrm{Am}$ & Yes & {$[37,40,46,47,66]$} \\
\hline batzelladine E (30) & Batzella sp. & Bahamas, North Atlantic Ocean & 1996 & 2 & n.t. & Yes & {$[35,66]$} \\
\hline batzelladine F (31) & Batzella sp. & Jamaica, North Atlantic Ocean & 1997 & 2 & $\mathrm{Am}$ & Yes & {$[30,39,42,67]$} \\
\hline batzelladine G (32) & Batzella sp. & Jamaica, North Atlantic Ocean & 1997 & 2 & $\mathrm{Av}$ & No & [67] \\
\hline batzelladine $\mathrm{H}(33)$ & Batzella sp. & Jamaica, North Atlantic Ocean & 1997 & 2 & $\mathrm{Av}$ & No & [67] \\
\hline batzelladine I (34) & Batzella sp. & Jamaica, North Atlantic Ocean & 1997 & 2 & $\mathrm{Av}$ & No & [67] \\
\hline dehydrobatzelladine C (35) & Monanchora arbuscula & Belize, North Atlantic Ocean & 2000 & 2 & $\mathrm{Av}, \mathrm{Am}, \mathrm{At}$ & Yes & {$[43,53,73]$} \\
\hline batzelladine J (36) & Monanchora unguifera & Panama, North Atlantic Ocean & 2005 & 3 & n.t. & No & [59] \\
\hline batzelladine K (37) & Monanchora unguifera & Jamaica, North Atlantic Ocean & 2007 & 1 & n.t. & No & [73] \\
\hline batzelladine L (38) & Monanchora unguifera & Jamaica, North Atlantic Ocean & 2007 & 2 & Av, Am, At & No & [73] \\
\hline batzelladine M (39) & Monanchora unguifera & Jamaica, North Atlantic Ocean & 2007 & 2 & Av, Am, At & No & [73] \\
\hline batzelladine $\mathrm{N}(\mathbf{4 0})$ & Monanchora unguifera & Jamaica, North Atlantic Ocean & 2007 & 2 & $\mathrm{Av}, \mathrm{At}$ & No & [73] \\
\hline clathriadic acid (41) & Clathria calla & Martinique, North Atlantic Ocean & 2009 & 1 & $\mathrm{Am}$ & No & [68] \\
\hline merobatzelladine A (42) & Monanchora sp. & Amami-Oshima Island, North Pacific Ocean & 2009 & 1 & $\mathrm{Am}$ & No & {$[50,69]$} \\
\hline merobatzelladine B (43) & Monanchora sp. & Amami-Oshima Island, North Pacific Ocean & 2009 & 1 & $\mathrm{Am}$ & Yes & [69] \\
\hline norbatzelladine A (44) & Monanchora arbuscula & Guadeloupe Island, North Atlantic Ocean & 2009 & 3 & Am, At & No & [68] \\
\hline norbatzelladine L (45) & Clathria calla & Martinique, North Atlantic Ocean & 2009 & 2 & Am, At & No & [68] \\
\hline dinorbatzelladine A (46) & Monanchora arbuscula & Guadeloupe island, North Atlantic Ocean & 2009 & 3 & Am, At & No & [68] \\
\hline dinorbatzelladine B (47) & Monanchora arbuscula & Guadeloupe island, North Atlantic Ocean & 2009 & 3 & n.t. & No & [68] \\
\hline dinordehydrobatzelladine B (48) & Monanchora arbuscula & Guadeloupe island, North Atlantic Ocean & 2009 & 3 & Am, At & No & [68] \\
\hline dihomodehydrobatzelladine C (49) & Monanchora arbuscula & Guadeloupe island, North Atlantic Ocean & 2009 & 2 & Am, At & No & [68] \\
\hline batzellamide A (50) & Monanchora arbuscula & Rio de Janeiro state, South Atlantic Ocean & 2015 & 2 & n.t. & No & [70] \\
\hline hemibatzelladine J (51) & Monanchora arbuscula & Rio de Janeiro state, South Atlantic Ocean & 2015 & 2 & n.t. & No & [70] \\
\hline$\Delta^{19}$-hemibatzelladine J (52) & Monanchora arbuscula & Rio de Janeiro state, South Atlantic Ocean & 2015 & 2 & n.t. & No & [70] \\
\hline$\Delta^{200}$-hemibatzelladine J (53) & Monanchora arbuscula & Rio de Janeiro state, South Atlantic Ocean & 2015 & 2 & n.t. & No & [70] \\
\hline
\end{tabular}

$\mathrm{Am}$, antimicrobial activity; $\mathrm{Av}$, antiviral activity; At, antitumor activity; and n.t., not tested. 
Since 1989, the number of new TGA discovered each year is considered as almost constant, although it should be noted that in some years no new TGA were described (Figure 2).

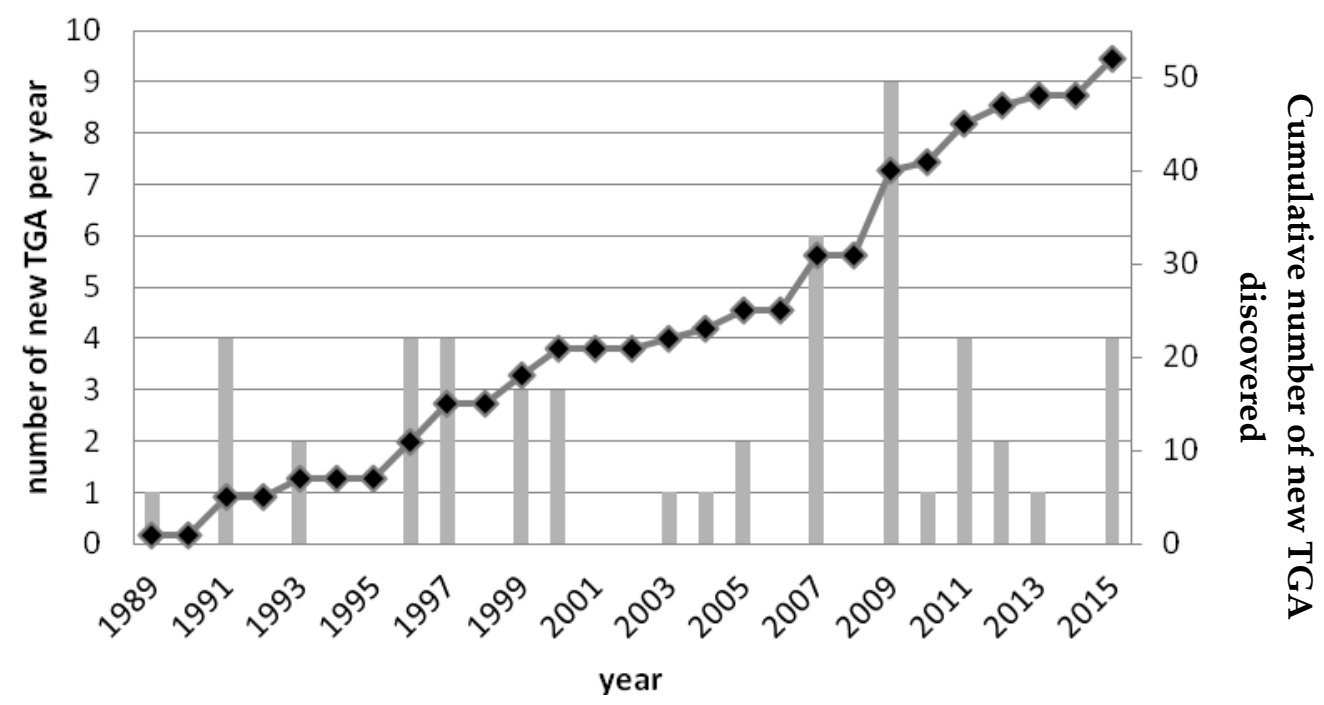

Figure 2. Number of new TGA discovered since 1989. The number of TGA discovered per year (grey bars) and the cumulative data representing the total number of TGA discovered (black curve) are presented from 1989 to 2015.

\subsection{TGA Structures}

Each TGA is structurally closely related to the others. Crambescidins-like GA differ from one another, by the C-8 spiro ring, the presence or absence of a hydroxyl group at $\mathrm{C}-13$ or the nature of the side chain terminus at C-14.

The structures of 22 related crambescidin-like GA are summarized in Figure 3.

Other derivatives such as 13,14,15-isocrambescidin 800 (6), crambidin (7) or 16ß-hydroxycrambescidin 359 (16) have also been isolated (Figure 4).

A

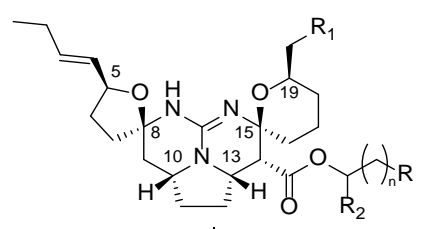

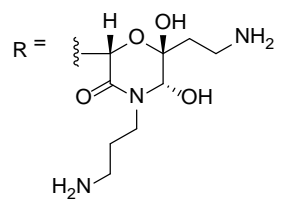

monanchocidin A (18): $\mathrm{R}_{1}=\mathrm{H}, \mathrm{R}_{2}=\mathrm{Et}, n=13$

monanchocidin D (21): $\mathrm{R}_{1}=\mathrm{H}, \mathrm{R}_{2}=\mathrm{H}, n=13$

monanchocidin E (22): $\mathrm{R}_{1}=\mathrm{H}, \mathrm{R}_{2}=\mathrm{Et}, n=12$<smiles>[R7]I=C(C)C(=O)N(CCCN)CCCCN</smiles>

monanchomycalin A (23):

$\mathrm{R}_{1}=\mathrm{Et}, \mathrm{R}_{2}=\mathrm{H}, n=14$

monanchomycalin B (24):

$\mathrm{R}_{1}=\mathrm{H}, \mathrm{R}_{2}=\mathrm{H}, n=14$

Figure 3. Cont. 
B

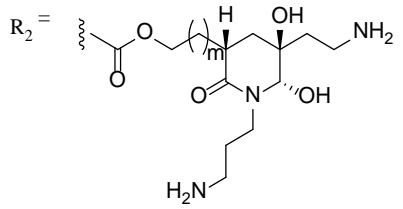

monanchocidin $B$ (19):

$\mathrm{R}_{1}=\mathrm{R}_{3}=\mathrm{H}, m=13$

monanchocidin $\mathrm{C}(\mathbf{2 0})$ :

$\mathrm{R}_{1}=\mathrm{R}_{3}=\mathrm{H}, m=14$

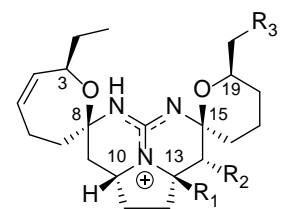

crambescidin 359 (11): $\mathrm{R}_{1}=\mathrm{R}_{2}=\mathrm{R}_{3}=\mathrm{H}$

crambescidin 431 (12): $\mathrm{R}_{1}=\mathrm{R}_{3}=\mathrm{H}, \mathrm{R}_{2}=\mathrm{COOEt}$

crambescidin acid (14): $\mathrm{R}_{1}=\mathrm{R}_{3}=\mathrm{H}, \mathrm{R}_{2}=\mathrm{COOH}$

$$
\mathrm{R}_{2}=\prod_{\mathrm{O}} \mathrm{O} \mathrm{H}_{\mathrm{R}}
$$

neofolitispate 1 (8): $\mathrm{R}_{1}=\mathrm{R}_{3}=\mathrm{H}, \mathrm{R}_{4}=\mathrm{COOMe}, n=15$

neofolitispate 2 (9): $\mathrm{R}_{1}=\mathrm{R}_{3}=\mathrm{H}, \mathrm{R}_{4}=\mathrm{COOMe}, n=14$

neofolitispate 3 (10): $\mathrm{R}_{1}=\mathrm{R}_{3}=\mathrm{H}, \mathrm{R}_{4}=$ COOMe, $n=13$

crambescidic acid (15): $\mathrm{R}_{1}=\mathrm{R}_{3}=\mathrm{H}, \mathrm{R}_{4}=\mathrm{COOH}, n=14$

ptilomycalin D (17): $\mathrm{R}_{1}=\mathrm{R}_{3}=\mathrm{H}, \mathrm{R}_{4}=\mathrm{Me}, n=14$

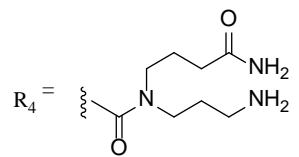

crambescidin 826 (13):

$\mathrm{R}_{1}=\mathrm{R}_{3}=\mathrm{H}, n=16$

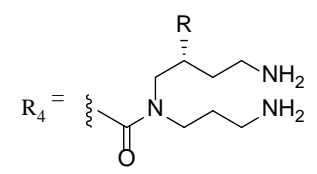

ptilomycalin A (1):

$\mathrm{R}_{1}=\mathrm{R}_{3}=\mathrm{R}=\mathrm{H}, n=14$

crambescidin 800 (2):

$\mathrm{R}_{1}=\mathrm{R}_{3}=\mathrm{H}, \mathrm{R}=\mathrm{OH}, n=14$ crambescidin 816 (3):

$\mathrm{R}_{1}=\mathrm{R}=\mathrm{OH}, \mathrm{R}_{3}=\mathrm{H}, n=14$

crambescidin 830 (4):

$\mathrm{R}_{1}=\mathrm{R}=\mathrm{OH}, \mathrm{R}_{3}=\mathrm{H}, n=15$

crambescidin 844 (5):

$\mathrm{R}_{1}=\mathrm{R}=\mathrm{OH}, \mathrm{R}_{3}=\mathrm{H}, n=16$

monanchomycalin C (25):

$\mathrm{R}_{1}=\mathrm{R}=\mathrm{H}, \mathrm{R}_{3}=\mathrm{Et}, n=14$

Figure 3. Related (A) C-8 cycloheptanic spiro ring and (B) C-8 cyclopentanic spiro ring crambescidin-like GA.

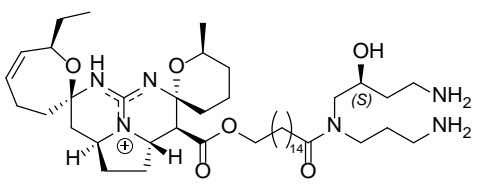

13,14,15-isocrambescidin 800 (6)

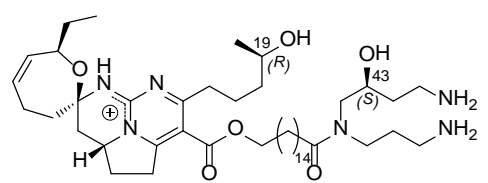

Crambidine (7)

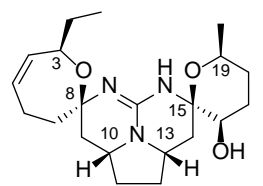

16ß-hydroxycrambescidin 359

(16)

Figure 4. Non-related crambescidin-like GA. 
Compared to crambescidin-like GA, batzelladines-like GA present more structural variations. Structurally, all of the batzelladines share a decahydro- or octahydro-5,6,8b-triazaacenaphthalene core with different degrees of oxidation. Batzelladines A-I (26-34) all possess at least one tricyclic guanidine core that contains either a syn or anti stereo relationship of the angular hydrogens that flank the pyrrolidine nitrogen [76]. To this, tricyclic guanidine core are connected, through an ester linkage, and additional guanidine fragments of varying complexity. Batzelladines F (31), G (32), and L (38) all possess an additional tricyclic hydroxy-guanidine fragment, while the simplest members of the family, batzelladines C (28), D (29), and E (30), possess a common 4-guanidino-butyl unit. The more complex batzelladines, A (26) and B (27), are attached to an analogue of crambescin A (54) (Figure 5). Batzelladines F (31) and J (36) are composed of two 5,6,6a-triaza-acenaphthalene cores linked via an aliphatic chain.

The structures of several members of the batzelladines have been revised since their original isolation. The originally proposed structures were based on chemical degradation studies, NMR spectroscopy analysis (1D and 2D), and comparison of the data to previously reported polycyclic guanidine such as ptilomycalin A (1). Since the original isolation work, the structures of batzelladines A (26), D (29), E (30), and F (31) have all been revised to their current structures after their partial or total synthesis $[27-30,35,39]$. As a consequence of these reassignments, the relative stereochemistry of batzelladines $\mathrm{G}$ (32), H (33), and I (34) has been reexamined [30].

The current structures of 22 related batzelladine-like GA are summarized in Figure 6.

Other batzelladine-like GA have been isolated such as batzelladine C (28), K (37), and E (30); dehydrobatzelladine C (35); clathriadic acid (41); and batzellamide A (50) (Figure 7).

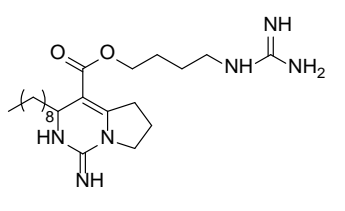

$$
\text { crambescin A (54) }
$$

Figure 5. Crambescin A (54).

\section{A}

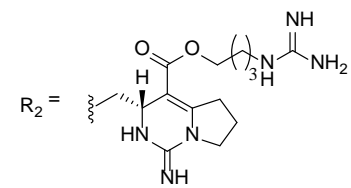

batzelladine A (26):

$\mathrm{R}_{1}=\mathrm{H}, n=8, m=8$

norbatzelladine A (44):

$\mathrm{R}_{1}=\mathrm{H}, n=8, m=7$

dinorbatzelladine A (46):

$\mathrm{R}_{1}=\mathrm{H}, n=8, m=6$
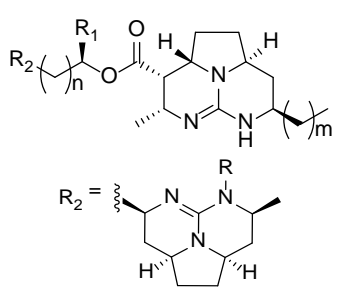

batzelladine $\mathrm{F}$ (31):

$\mathrm{R}_{1}=\mathrm{CH}_{3}, \mathrm{R}=\mathrm{H}, n=7, m=6$

batzelladine $G$ (32):

$\mathrm{R}_{1}=\mathrm{CH}_{3}, \mathrm{R}=\mathrm{OH}, n=7, m=8$

batzelladine $\mathrm{L}$ (38):

$\mathrm{R}_{1}=\mathrm{CH}_{3}, \mathrm{R}=\mathrm{H}, n=7, m=8$

norbatzelladine $\mathrm{L}$ (45):

$\mathrm{R}_{1}=\mathrm{CH}_{3}, \mathrm{R}=\mathrm{H}, n=7, m=7$

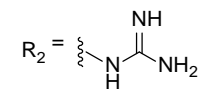

batzelladine $\mathrm{D}$ (29):

$\mathrm{R}_{1}=\mathrm{H}, m=7, n=3$

Figure 6. Cont. 
B

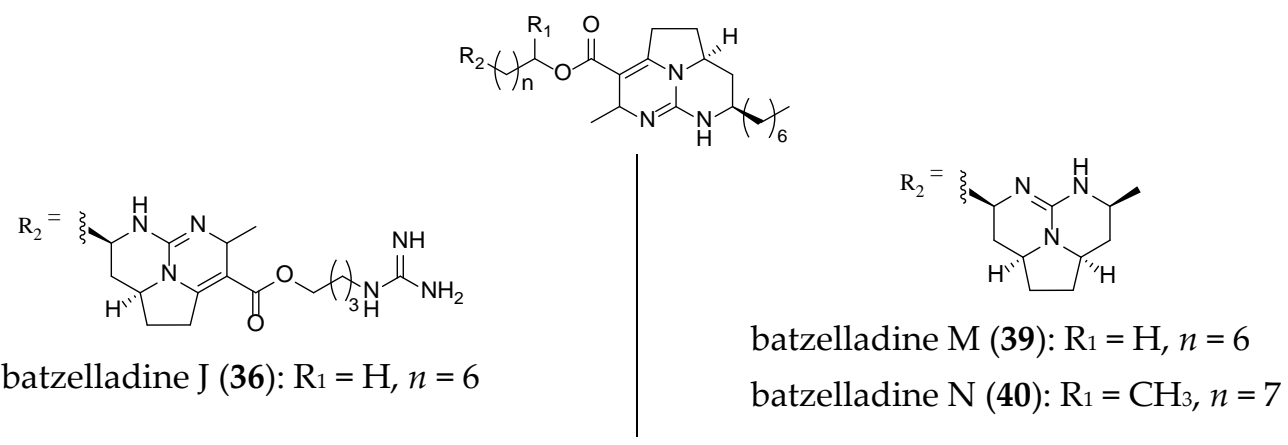

C<smiles>[R]COC(=O)c1c([R])nc2[nH]n3c2c1CC[C@@H]3CC(C)C</smiles>

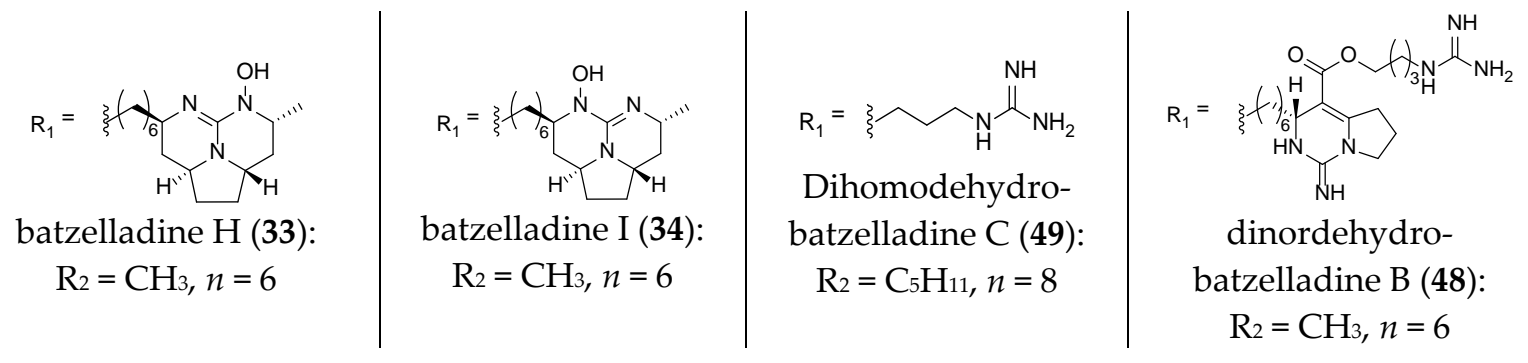

D

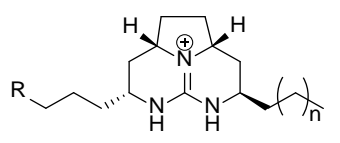

merobatzelladine A (42): $\mathrm{R}=\xi(n=5$

merobatzelladine B (43): $\mathrm{R}=\mathrm{Et}, n=3$

$\mathbf{F}$

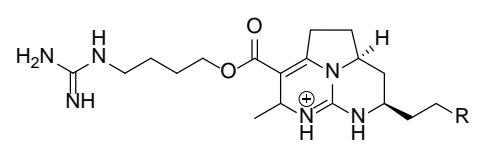

hemibatzelladine J (51): $\mathrm{R}=$

$\Delta^{19}$-hemibatzelladine J (52): $\mathrm{R}=$

$\Delta^{20}$-hemibatzelladine J (53): $\mathrm{R}=\xi \mathrm{OH}_{\mathrm{OH}}$
E

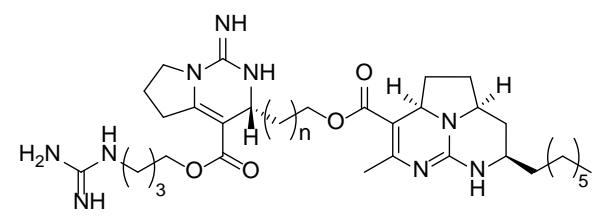

batzelladine B (27): $n=8$

dinorbatzelladine $\mathrm{B}(47): n=6$

Figure 6. Related batzelladine-like GA with different right-handed tricycles. 


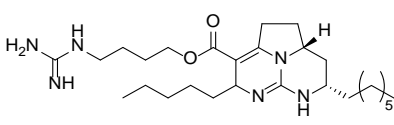

batzelladine C (28)

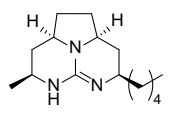

batzelladine K (37)

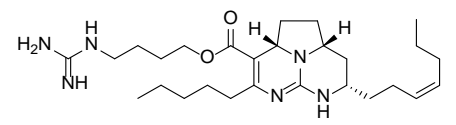

batzelladine E (30)

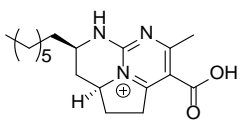

clathriadic acid (41)

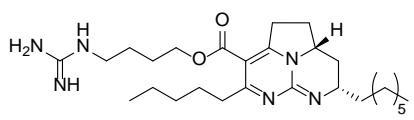

dehydrobatzelladine C (35)

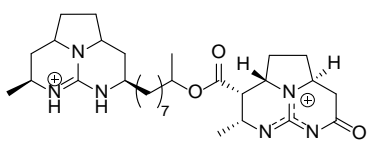

batzellamide A (50)

Figure 7. Unrelated batzelladine-like GA.

In summary, the structurally unique tricyclic guanidinium ring system (hydro-5,6,6atriazaacenapthalene) that defines this class of natural products can be found in over 53 different alkaloids. While each of these natural products share this common structural motif, the substituents around the tricyclic core of these molecules leads to a significant structural diversity, which relate to a wide-range of biological properties. For instance, a large number of these molecules including batzelladine F (31) and ptilomycalin A (1) feature esters that tether the tricyclic core to a diverse array of different functional groups, including other tricyclic guanidine subunits. The other area of structural diversity within this family of alkaloids is both the $\mathrm{C} 1$ and the $\mathrm{C} 8$ alkyl chains, which vary in terms of length, units of unsaturation, and oxidation. Remote oxidation of the alkyl branches is characteristic of the crambescidin alkaloids, including ptilomycalin A (1) and crambescidin 359 (11), which feature two spirocyclic hemiaminals as well as the tricyclic guanidine framework. In addition to structural diversity, batzelladines-like GA and crambescidins-like GA alkaloids feature different stereochemical configurations of the tricyclic core. Both the trans- and cis-configurations of the pyrrolidine subunit have been reported in this class of natural products. Batzelladine $\mathrm{F}$ (31) highlights this stereochemical diversity as it contains two distinct tricyclic guanidine subunits, with each featuring one of the pyrrolidine configurations. The stereochemical diversity is generally limited to the configuration of the pyrrolidine unit, as all of the alkaloids in this class feature a trans relationship between the $\mathrm{C} 4$ (and/or C6) proton and the $\mathrm{C} 1$ (and/or C8) alkyl chain, with the exception of merobatzelladines A (42) and B (43). Both natural products feature a cis relationship between the $\mathrm{C} 6$ proton and the $\mathrm{C} 8$ alkyl chain.

\subsection{TGA Classification}

Different guanidine alkaloids classifications can be made, and, as such, Santos et al. (2015) have described four GA chemotypes [70]. The first class is constituted of a monocyclic pyrimidinamine skeleton, for example, crambescin C1 (55) or the bicyclic cyclopentapyrimidinamine skeleton, such as crambine A (56) (Figure 8). The second one is a tricyclic triazaacenaphthylene skeleton, which only contains one guanidine moiety like crambescidins, and the third one possess the same skeleton as for class 2, but contains, at least, one more guanidine moiety, as can be seen in the case of most batzelladines. The fourth one is a tricyclic cyclopentaquinazolinamine skeleton like netamine $\mathrm{M}$ (57) or ptilocaulin (58).

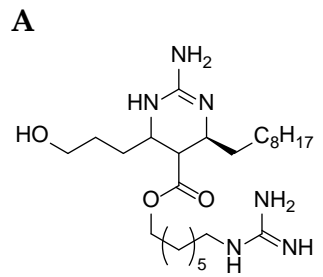

crambescin C1 (55)
B

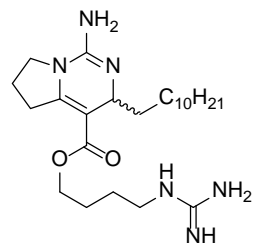

crambine A (56)
C

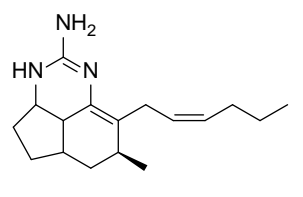

netamine M (57)
D

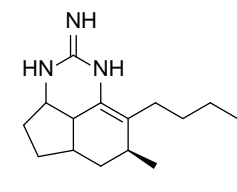

ptilocaulin (58)

Figure 8. (A) Crambescin C1 (55); (B) crambine A (56); (C) netamine M (57); and (D) ptilocaulin (58). 
Another classification can be made with the same first, second and fourth classes, and a modified third class describing pentacyclic triazaacenaphthylene skeletons like crambescidins (1-25) (Table 3).

Without taking into account any genus revision made, some observations may be outlined. According to the data reported, Monanchora is the most studied genus (Tables 1 and 2). Some species seem to produce both the crambescidins and batzelladines classes as is illustrated with Monanchora unguifera, which produces $16 \beta$-hydroxycrambescidin (16), crambescidic acid (15) and batzelladines J-L (36-38) (Tables 1 and 2). Other genera seem to produce only one TGA family. For example, to date, Batzella sp. was only shown to produce batzelladines A-I (26-34).

Interestingly, a chemotaxonomic study suggested that the biogenetically related guanidine alkaloids isolated from Crambe crambe, Monanchora arbuscula, Ptilocaulis spiculifer, and Hemimycale sp., should eventually be united in a single genus, preferentially Crambe [53].

Table 3. GA classes.

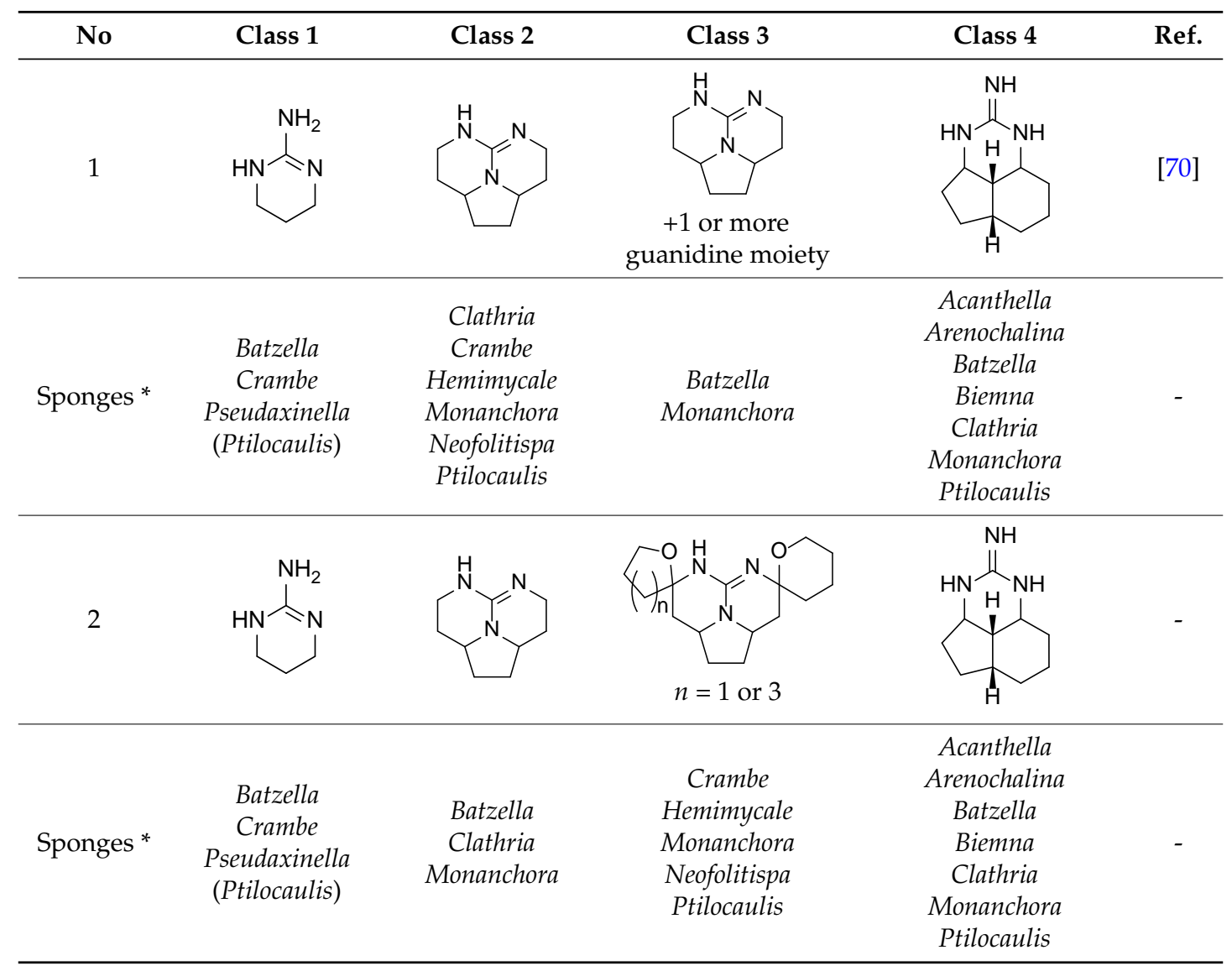

* Sponges without any genus revision made.

\subsection{Analytical Tools for TGA Structural Analysis}

TGA structural determinations have been accomplished based on extensive NMR (1D and 2D) and MS analyses, and chemical degradation.

The following section is a guideline for the structure determination of crambescidin- or batzelladine-like GA derivatives by their characteristic fragments via the use of NMR and MS analyses.

\subsubsection{NMR Spectroscopy}

TGA NMR spectra have a high content of information. Due to the relative signal richness, the ${ }^{1} \mathrm{H}-{ }^{1} \mathrm{H}$ COSY experiment is appropriate in helping to find whether one or another TGA class is present 
by analyzing the NMR spectra between 0.8 and $5 \mathrm{ppm}$. Nonetheless, several characteristic signals from different atoms listed below (Figure 9) should be found in the ${ }^{1} \mathrm{H}$ NMR spectra (Table 4).

A

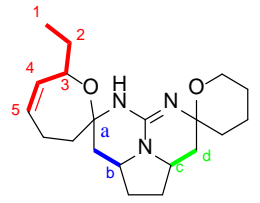

B<smiles></smiles>

Figure 9. Current numbering scheme for: (A) C-8 cycloheptanic spiro ring crambescidin-like GA; and (B) batzelladine-like GA.

Table 4. Characteristic TGA signals.

\begin{tabular}{ccc}
\hline Atom Number & Crambescidin-Like GA Signals & Batzelladine-Like GA Signals \\
\hline $\mathrm{H}_{\mathrm{a}}{ }^{*}$ & $\mathrm{dd}$ from 2.8 to $2.5 \mathrm{ppm}$ & $\mathrm{m}$ from 2.8 to $2.5 \mathrm{ppm}$ \\
$\mathrm{H}_{\mathrm{b}}{ }^{*}$ & $\mathrm{~m}$ from 4.6 to $3.9 \mathrm{ppm}$ & $\mathrm{m}$ from 4.6 to $3.9 \mathrm{ppm}$ \\
$\mathrm{H}_{\mathrm{c}}$ & $\mathrm{d}$ toward $4.3 \mathrm{ppm}$ & $\mathrm{m}$ toward $4.3 \mathrm{ppm}$ \\
$\mathrm{H}_{\mathrm{d}}^{*}$ & $\mathrm{~d}$ from 3.5 to $2.9 \mathrm{ppm}$ & $\mathrm{dd}$ from 3.5 to $2.9 \mathrm{ppm}$ \\
$\mathrm{H}_{4}{ }^{*}$ et $\mathrm{H}_{5}$ * double bond & $2 \mathrm{~m}$ toward $5.5 \mathrm{ppm}$ & No signal \\
\hline
\end{tabular}

*: for a, b, c, d, 4 and 5 attributions, see above; d, doublet; dd, doublet of doublets; dt, doublet of triplets; $\mathrm{m}$, multiplet.

Crambescidin Case: Ptilomycalin A (1)

As an example, we choose ptilomycalin A (1), which is part of the pentacyclic TGA class.

First of all, the $\mathrm{H}_{1}$ signal (triplet) and the $\mathrm{H}_{4}$ and $\mathrm{H}_{5}$ signals of the double bond are very characteristic. There are also clear correlations from $\mathrm{H}_{1}$ to $\mathrm{H}_{5}$, and finally, the NMR chemical shifts of $\mathrm{H}_{\mathrm{a}}, \mathrm{H}_{\mathrm{b}}, \mathrm{H}_{\mathrm{c}}$ and $\mathrm{H}_{\mathrm{d}}$ are also very characteristic within the crambescidin family (Figure 10) (Table 4).

A

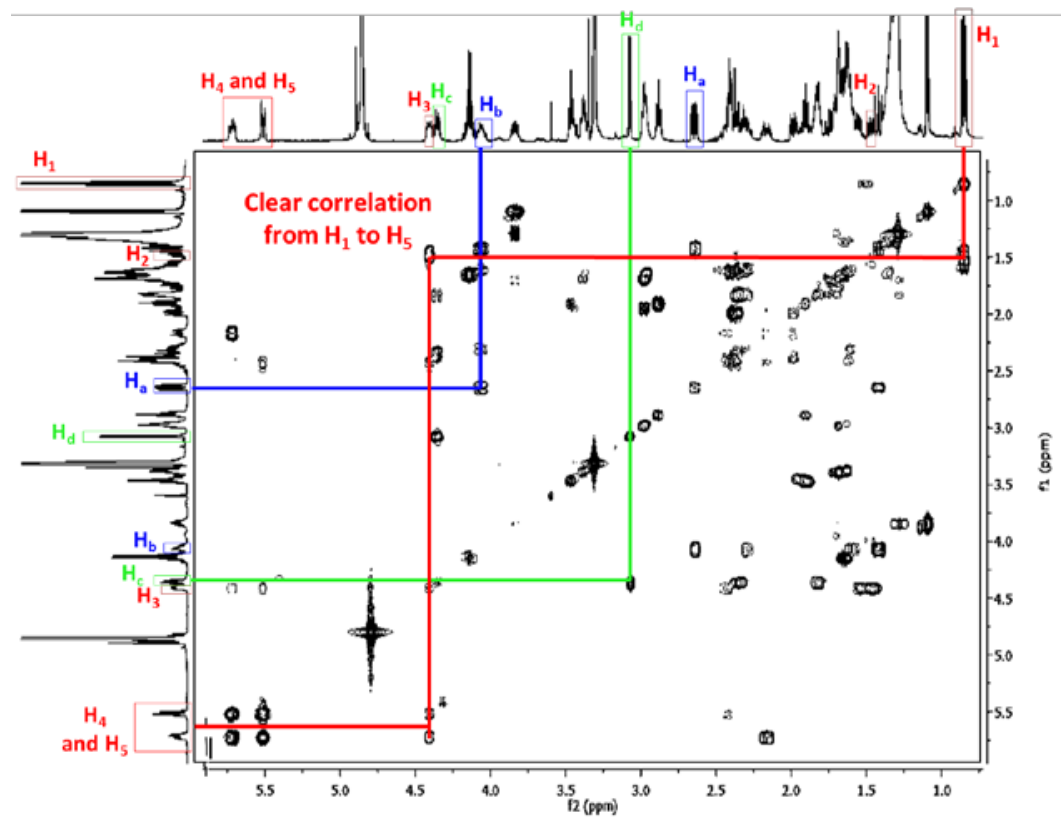

Figure 10. Cont. 
B

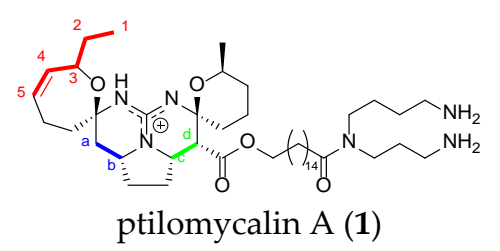

Figure 10. (A) Ptilomycalin A (1) ${ }^{1} \mathrm{H}^{-1} \mathrm{H}$ COSY NMR spectrum in $\mathrm{CD}_{3} \mathrm{OD}$ (personal data); and (B) labeled ptilomycalin A (1).

Batzelladine Case: Batzelladine F (31)

In general, all the NMR signals reported in Table 4 are more shielded in batzelladines than in crambescidins. Moreover, the NMR spectra are more complex and are often different since the guanidinium core can be once or more dehydrogenated.

Within the tricyclic TGA class 2, we used the example of batzelladine F (31).

The major difference between batzelladine $\mathrm{F}$ and ptilomycalin A spectra is the absence of the signals for the protons $\mathrm{H}_{4}$ and $\mathrm{H}_{5}$, and the corresponding correlation. On the other hand, two correlations are very characteristic within batzelladines: $\mathrm{H}_{\mathrm{a}}$ with $\mathrm{H}_{\mathrm{b}}$, and $\mathrm{H}_{\mathrm{c}}$ with $\mathrm{H}_{\mathrm{d}}$ (Figure 11).

A

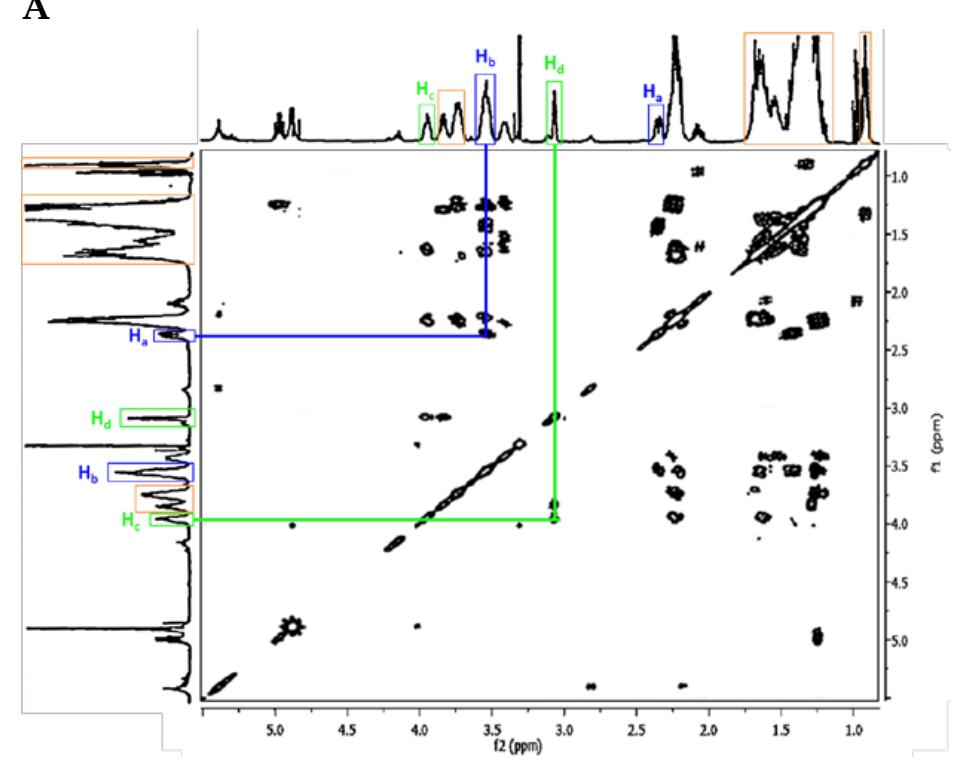

B

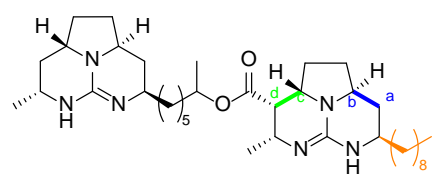

batzelladine F (31)

Figure 11. (A) Batzelladine $\mathrm{F}(31){ }^{1} \mathrm{H}_{-}{ }^{1} \mathrm{H}$ COSY NMR spectrum in $\mathrm{CD}_{3} \mathrm{OD}$ (adapted from Patil et al. [67]); and (B) labeled batzelladine $\mathrm{F}(\mathbf{3 1})$.

\subsubsection{Mass Spectrometry}

Several TGA were detected by positive electrospray mass spectrometry ionization studies. Usually, authors notify the TGA quasi-molecular ion $[\mathrm{M}+\mathrm{H}]^{+}$with the exception of batzelladines $\mathrm{M}$ (39) and $\mathrm{N}(40)$, which were detected through their dicharged ion $[\mathrm{M}+2 \mathrm{H}]^{2+}[73]$. On the other hand, both quasi-molecular and discharged ions were observed for batzelladine $\mathrm{L}(38)$ and monanchomycalin C (25). Mass spectrometry data for TGA are summarized in Table 5. 
Table 5. TGA Mass Spectrometry (MS) data.

\begin{tabular}{|c|c|c|}
\hline Metabolites & $m / z\left([\mathrm{M}+\mathrm{H}]^{+}\right.$Unless Specified) and $\Delta \mathrm{ppm}$ Found & Ref. \\
\hline ptilomycalin A (1) & $977.7915(1.0 \mathrm{mmu})$ for the bis(trifluoroacetyl) derivative & [51] \\
\hline crambescidin 800 (2) & $801.6205(1.3 \mathrm{mmu})$ & [55] \\
\hline crambescidin 816 (3) & $817.6151(1.6 \mathrm{mmu})$ & [55] \\
\hline crambescidin $830(4)$ & $831.6300(2.3 \mathrm{mmu})$ & [55] \\
\hline crambescidin 844 (5) & $845.6471(0.9 \mathrm{mmu})$ & [55] \\
\hline 13, 14,15 -isocrambescidine $800(6)$ & $927.6521(1.3 \mathrm{mmu})$ for the acetylated compound & [52] \\
\hline crambidine (7) & $967.6415(6.8 \mathrm{mmu})$ for the acetylated compound & [52] \\
\hline neofolitispate $1(8)$ & 686 (no HRMS data) & [57] \\
\hline neofolitispate 2 (9) & 672 (no HRMS data) & [57] \\
\hline neofolitispate $3(\mathbf{1 0})$ & 658 (no HRMS data) & [57] \\
\hline crambescidin 359 (11) & $359.2567(0.6 \mathrm{mmu})$ & [53] \\
\hline crambescidin 431 (12) & $431.2780(0.4 \mathrm{mmu})$ & [53] \\
\hline crambescidin 826 (13) & $827.6389(1.5 \mathrm{mmu})$ & [54] \\
\hline crambescidin acid (14) & $404.2541(2.2 \mathrm{mmu})$ & [58] \\
\hline crambescidic acid (15) & $658.4781(1.4 \mathrm{mmu})$ & [59] \\
\hline 16ß-hydroxycrambescidin 359 (16) & $376.2617(1.7 \mathrm{mmu})$ & [73] \\
\hline ptilomycalin D (17) & $627.4994 *$ & [60] \\
\hline monanchocidin (A) (18) & $859.6267(3.0 \mathrm{mmu})$ & [61] \\
\hline monanchocidin B (19) & $831.5978(3.4 \mathrm{mmu})$ & [62] \\
\hline monanchocidin C (20) & $845.6150(4.0 \mathrm{mmu})$ & [62] \\
\hline monanchocidin D (21) & $831.5920(3.4 \mathrm{mmu})$ & [62] \\
\hline monanchocidin E (22) & $845.6120(1.0 \mathrm{mmu})$ & [62] \\
\hline monanchomycalin A (23) & $813.6574(0.2 \mathrm{mmu})$ & [63] \\
\hline monanchomycalin B (24) & $785.6259(0.4 \mathrm{mmu})$ & [63] \\
\hline monanchomycalin C (25) & $813.6578(0.3 \mathrm{mmu})$ and $[\mathrm{M}+2 \mathrm{H}]^{2+} 407.3336(0.7 \mathrm{mmu})$ & {$[64]$} \\
\hline batzelladine A (26) & $768.5839(2.4 \mathrm{mmu})$ & [66] \\
\hline batzelladine B (27) & $738.5356(3.8 \mathrm{mmu})$ & [66] \\
\hline batzelladine C (28) & $489.3903(1.4 \mathrm{mmu})$ & [66] \\
\hline batzelladine D (29) & $463.3740 * *$ & [66] \\
\hline batzelladine E (30) & $487.3728(3.2 \mathrm{mmu})$ & [66] \\
\hline batzelladine F (31) & $624.5096(0.6 \mathrm{mmu})$ & [67] \\
\hline batzelladine G (32) & 668,5353 (1.3 mmu) & [67] \\
\hline batzelladine $\mathrm{H}(33)$ & \multirow{2}{*}{$609.4488(0.4 \mathrm{mmu})$} & [67] \\
\hline batzelladine I (34) & & [67] \\
\hline dehydrobatzelladine C (35) & $487.3711(4.9 \mathrm{mmu})$ & [53] \\
\hline batzelladine J (36) & $750.5361(3.3 \mathrm{mmu})$ & [59] \\
\hline batzelladine K (37) & $250.2322(3.9 \mathrm{mmu})$ & [73] \\
\hline batzelladine L (38) & $653.5458(2.4 \mathrm{mmu})$ and $[\mathrm{M}+2 \mathrm{H}]^{2+} 327.2798(1.8 \mathrm{mmu})$ & [73] \\
\hline batzelladine M (39) & {$[\mathrm{M}+2 \mathrm{H}]^{2+} 298.2399(1.0 \mathrm{mmu})$} & [73] \\
\hline batzelladine $\mathrm{N}(40)$ & {$[\mathrm{M}+2 \mathrm{H}]^{2+} 312.2546(1.0 \mathrm{mmu})$} & [73] \\
\hline clathriadic acid (41) & $318.2173(1.0 \mathrm{mmu})$ & [68] \\
\hline merobatzelladine A (42) & $360.3444(6.6 \mathrm{mmu})$ & [69] \\
\hline merobatzelladine B (43) & $306.2909(7.0 \mathrm{mmu})$ & [69] \\
\hline norbatzelladine A (44) & $754.5705(0.7 \mathrm{mmu})$ & [68] \\
\hline norbatzelladine L (45) & $639.5327(0.3 \mathrm{mmu})$ & [68] \\
\hline dinorbatzelladine A (46) & $740.5547(0.9 \mathrm{mmu})$ & {$[68]$} \\
\hline dinorbatzelladine B (47) & $710.5074(1.2 \mathrm{mmu})$ & [68] \\
\hline dinordehydrobatzelladine B (48) & $708.4919(1.0 \mathrm{mmu})$ & [68] \\
\hline dihomodehydrobatzelladine C (49) & $515.4064(1.3 \mathrm{mmu})$ & {$[68]$} \\
\hline batzellamide A (50) & $541.3878(1.2 \mathrm{mmu})$ & [70] \\
\hline hemibatzelladine J (51) & $449.3238(0.2 \mathrm{mmu})$ & [70] \\
\hline$\Delta^{19}$-hemibatzelladine J (52) & \multirow{2}{*}{$447.3092(0.8 \mathrm{mmu})$} & [70] \\
\hline$\Delta^{200}$-hemibatzelladine J (53) & & [70] \\
\hline
\end{tabular}

* Calculated $\mathrm{m} / \mathrm{z}$ value: 626.4975 ; reported $\mathrm{m} / \mathrm{z}$ value: $627.4994 ;{ }^{* *}$ not specified. 
Tandem mass spectrometry (MS²) experiments were also performed to confirm a hypothesis or provide additional information concerning the TGA side chains, as reported in Table 6.

Table 6. Characteristic MS ${ }^{2}$ TGA signals.

\begin{tabular}{cccc}
\hline$m / z$ Fragment & $m / z$ Fragment Loss & Fragment & Ref. \\
\hline 358 (or 359) & & Crambescidin core & {$[53-55,59]$} \\
\hline 322 or 336 or 350 & & Batzelladine core $+n=6,7$ or 8 carbon side chain & {$[53,66-68,73]$} \\
\hline 114 & 113 & & {$[53,59,66]$} \\
& 101 & & \\
& &
\end{tabular}

\section{Biological Activities}

TGA exhibited a wide range of biological activities with mainly antiviral, antimicrobial (including antifungal, antibacterial, anti-yeast, and antiparasitic), and antitumor properties.

\subsection{Antiviral Activities}

Several TGA derivatives were evaluated for their antiviral activities against different viruses such as Human immunodeficiency virus (HIV-1), Herpes simplex virus (HSV-1), and Human hepatitis B virus (HBV). The reported data for 17 TGA are summarized in Table 7.

Table 7. TGA antiviral activities.

\begin{tabular}{|c|c|c|c|c|c|c|}
\hline \multirow{2}{*}{$\mathrm{EC}_{50}(\mu \mathrm{M}$ Unless Specified $)$} & \multicolumn{3}{|c|}{ HIV-1 } & \multirow{2}{*}{ HSV-1 } & \multirow{2}{*}{ HBV } & \multirow{2}{*}{ Ref. } \\
\hline & $\begin{array}{l}\text { Human } \\
\text { PBMC }\end{array}$ & $\begin{array}{l}\text { Envelope-Mediated } \\
\text { Fusion }\end{array}$ & $\begin{array}{l}\text { gp120 Binding } \\
\text { to CD4 }\end{array}$ & & & \\
\hline ptilomycalin A (1) & 0.011 & n.t. & n.t. & $0.25 *$ & n.t. & [51] \\
\hline crambescidin $800(2)$ & 0.04 & $1-3$ & n.t. & $1.25 \mu \mathrm{g} /$ well $^{\mathrm{a}}$ & n.t. & {$[54,55,73]$} \\
\hline crambescidin $816(3)$ & n.t. & n.t. & n.t. & $1.25 \mu \mathrm{g} /$ well $^{\mathrm{a}}$ & n.t. & [55] \\
\hline crambescidin 844 (5) & n.t. & n.t. & n.t. & $1.25 \mu \mathrm{g} /$ well $^{\mathrm{a}}$ & n.t. & [55] \\
\hline 13,14,15-isocrambescidin $800(6)$ & n.t. & n.t. & n.t. & NA & n.t. & [56] \\
\hline neofolitispate 1 (8) & n.t. & n.t. & n.t. & n.t. & \multirow{3}{*}{$7.4^{* *}$} & \multirow{3}{*}{ [57] } \\
\hline neofolitispate $2(9)$ & n.t. & n.t. & n.t. & n.t. & & \\
\hline neofolitispate 3 (10) & n.t. & n.t. & n.t. & n.t. & & \\
\hline crambescidin 826 (13) & n.t. & $1-3$ & n.t. & n.t. & n.t. & [54] \\
\hline batzelladine A (26) & n.t. & n.t. & 29 & n.t. & n.t. & {$[66]$} \\
\hline batzelladine B (27) & n.t. & n.t. & 31 & n.t. & n.t. & {$[66]$} \\
\hline batzelladine C (28) & 7.7 & n.t. & n.t. & n.t. & n.t. & [73] \\
\hline batzelladine D (29) & n.t. & n.t. & 72 & n.t. & n.t. & {$[66]$} \\
\hline dehydrobatzelladine C (35) & 5.5 & n.t. & n.t. & n.t. & n.t. & [73] \\
\hline batzelladine L (38) & 1.6 & n.t. & n.t. & n.t. & n.t. & [73] \\
\hline batzelladine M (39) & 7.7 & n.t. & n.t. & n.t. & n.t. & [73] \\
\hline batzelladine $\mathrm{N}(40)$ & 2.4 & n.t. & n.t. & n.t. & n.t. & [73] \\
\hline
\end{tabular}

HIV, Human immunodeficiency virus; PBMC, Peripheral Blood Mononuclear cells; gp, glycoprotein; HSV, Herpes simplex virus; HBV, Human hepatitis B virus; n.t., not tested, NA, not active; * converted from $\mu \mathrm{M}$ to $\mu \mathrm{g} / \mathrm{mL} ;{ }^{* *}$ calculated from compound (9) molecular weight; ${ }^{a}$ Diffuse cytotoxicity at $1.25 \mu \mathrm{g} / \mathrm{well}$. 
In general, crambescidin-like GA seem to be more efficient against HIV compared to batzelladine-like GA (half maximal effective concentration $\left(\mathrm{EC}_{50}\right)$ around $1 \mathrm{mM}[66,73]$ ) with $\mathrm{EC}_{50}$ activities below $0.05 \mu \mathrm{M}[51,73]$. The stereochemistry of the molecule has a great influence on the antiviral activity. For example, 13,14,15-isocrambescidin (6) is not active against HSV-1 compared to crambescidins [56]. Ptilomycalin A (1) shows very potent anti-HIV-1 and anti-HSV-1 activities at a concentration of 0.011 and $0.25 \mu \mathrm{M}$, respectively [51], which makes it the best antiviral candidate.

Surprisingly, neofolitispates (8-10) are the only crambescidin-like GA derivatives that have been tested on HBV and exhibited an anti-HBV activity [57]. Unfortunately, few details have been reported.

On the other hand, batzelladines A-E (26-30) were shown to block the interaction between the surface of the HIV envelope glycoprotein gp120 and the extracellular domains of human CD4 receptor protein [77]. This binding is vital to the replication of the virus as it controls its entry into the human cells, since without access to the biochemical environment within the cell the virus is unable to replicate. As a consequence, batzelladines have a therapeutic interest in the treatment of HIV [76].

To date, batzelladine-like GA have not been tested against HSV or HBV viruses.

\subsection{Antimicrobial Activities}

TGA derivatives were tested against several bacteria (Mycobacterium tuberculosis, Staphylococcus aureus, Pseudomonas aeruginosa, and Mycobacterium intracellulare), yeast (Candida albicans), fungi (Cryptococcus neoformans and Aspergillus fumigatus), and parasites (Plasmodium falciparum, Tripanosoma cruzi, Leishmania infatum, and Trypanosoma brucei brucei). Table 8 reports all the antimicrobial activity results for 19 TGA tested.

Crambescidin 800 (2) and ptilomycalin A (1) exhibited potent activity against most bacteria, yeast, fungi, and parasites [68,73]. Curiously, they are poorly active on Mycobacterium intracellulare and are considered inactive on Mycobacterium tuberculosis (M. tuberculosis) [73]. Furthermore, $16 \beta$-hydroxycrambescidin (16), the only crambescidin-like GA bearing a hydroxyl group on its pentacycle, was not active against all the strains tested [73].

In some cases, Batzelladine-like GA present similar activities compared to crambescidin-like GA. Batzelladines C (28) and L (38) are often the more potent molecules [73]. Nevertheless, batzelladine M (39) is the less active TGA class 2 and surprisingly, the same authors showed batzelladine $N(40)$ to be nine times more efficient compared to batzelladine $\mathrm{M}$ (39) against $M$. tuberculosis (minimum inhibitory concentration (MIC) 3.18 and $28.5 \mu \mathrm{g} \cdot \mathrm{mL}^{-1}$, respectively), despite their chemical structures being closely related [73].

\subsection{Antitumoral Activities}

Over 20 TGA were tested for their cytotoxicity against several cancer cell lines such as prostate, ovary, breast, melanoma leukemia, pancreas, colon, and cervix (Table 9). 
Table 8. TGA antimicrobial activities.

\begin{tabular}{|c|c|c|c|c|c|c|c|c|c|c|c|c|c|c|c|c|c|}
\hline \multirow[b]{3}{*}{$\mathrm{IC}_{50}$ (Values are Expressed in $\mu \mathrm{g} / \mathrm{mL}$ Unless Specified) } & \multirow[b]{3}{*}{ 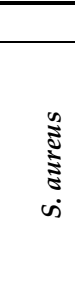 } & \multirow[b]{3}{*}{\begin{tabular}{l} 
S \\
\multirow{2}{*}{}
\end{tabular}} & \multicolumn{3}{|c|}{ Bacteria } & \multirow{3}{*}{ 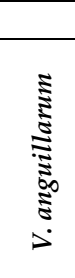 } & \multirow{3}{*}{ 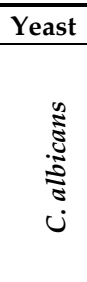 } & \multicolumn{2}{|c|}{ Fungi } & \multicolumn{7}{|c|}{ Parasites } & \multirow[b]{3}{*}{ Ref. } \\
\hline & & & \multirow{2}{*}{ 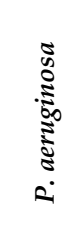 } & \multirow{2}{*}{ 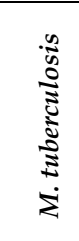 } & \multirow{2}{*}{ 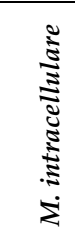 } & & & \multirow{2}{*}{ 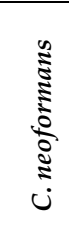 } & \multirow{2}{*}{ 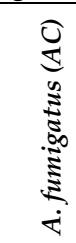 } & \multicolumn{3}{|c|}{ P. falciparum } & \multirow[b]{2}{*}{ 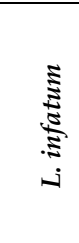 } & \multirow{2}{*}{ 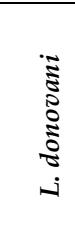 } & \multirow[b]{2}{*}{ 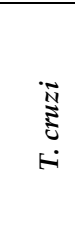 } & \multirow{2}{*}{ 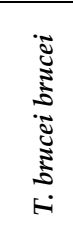 } & \\
\hline & & & & & & & & & & D6 Clone & W2 Clone & FcB1 & & & & & \\
\hline ptilomycalin A (1) & 0.25 & 0.30 & 1.0 & $>128$ & 10 & n.t. & 0.15 & 0.10 & 1.25 & 0.12 & 0.11 & $0.08^{*}$ & n.t. & 5.9 & n.t. & n.t. & {$[68,73]$} \\
\hline crambescidin 800 (2) & 0.20 & 0.35 & 0.95 & 46.5 & 15 & n.t. & 0.15 & 0.10 & 1.25 & 0.11 & 0.13 & n.t. & n.t. & 6.80 & n.t. & n.t. & [73] \\
\hline 16ß-hydroxycrambescidin 800 (16) & NA & NA & NA & $>128$ & NA & n.t. & NA & NA & NA & 3.8 & NA & NA & n.t. & n.t. & n.t. & n.t. & [73] \\
\hline batzelladine A (26) & n.t. & n.t. & n.t. & n.t. & n.t. & n.t. & n.t. & n.t. & n.t. & n.t. & n.t. & $0.2^{*}$ & n.t. & n.t. & n.t. & n.t. & [68] \\
\hline batzelladine C (28) & 0.20 & 0.30 & 10 & 34.7 & 0.9 & n.t. & 0.90 & 0.40 & 5.0 & 0.09 & 0.11 & n.t. & n.t. & 5.5 & n.t. & n.t. & [73] \\
\hline batzelladine D (29) & n.t. & n.t. & n.t. & n.t. & n.t. & n.t. & n.t. & n.t. & n.t. & n.t. & n.t. & n.t. & $0.9^{*}$ & n.t. & $29 *$ & n.t. & [70] \\
\hline batzelladine F (31) & n.t. & n.t. & n.t. & n.t. & n.t. & n.t. & n.t. & n.t. & n.t. & n.t. & n.t. & n.t. & $2.5^{*}$ & n.t. & $3.1^{*}$ & n.t. & [70] \\
\hline dehydrobatzelladine C (35) & 0.40 & 0.70 & NA. & 37.7 & 1.0 & n.t. & 1.0 & 0.6 & 20 & 0.073 & 0.13 & n.t. & n.t. & 5.70 & n.t. & n.t. & [73] \\
\hline batzelladine L (38) & 0.35 & 0.40 & 3.50 & 1.68 & 0.25 & n.t. & 0.40 & 0.55 & 2.5 & 0.073 & 0.10 & $0.2 *$ & $1.3^{*}$ & 1.90 & $1.3^{*}$ & n.t. & {$[68,73]$} \\
\hline batzelladine M (39) & 3.0 & 5.0 & NA & 28.5 & 3.50 & n.t. & 6.0 & 8.0 & NA & 0.21 & 0.27 & n.t. & n.t. & 8.50 & n.t. & n.t. & [73] \\
\hline batzelladine N (40) & n.t. & n.t. & n.t. & 3.18 & n.t. & n.t. & n.t. & n.t. & n.t. & n.t. & n.t. & n.t. & n.t. & n.t. & n.t. & n.t. & [73] \\
\hline clathriadic acid (41) & n.t. & n.t. & n.t. & n.t. & n.t. & n.t. & n.t. & n.t. & n.t. & n.t. & n.t. & $1.4^{*}$ & n.t. & n.t. & n.t. & n.t. & [68] \\
\hline merobatzelladine A (42) & n.t. & n.t. & n.t. & n.t. & n.t. & \multirow{2}{*}{$\mathrm{a}$} & n.t. & n.t. & n.t. & & 0.48 & & n.t. & n.t. & n.t. & 0.24 & [69] \\
\hline merobatzelladine B (43) & n.t. & n.t. & n.t. & n.t. & n.t. & & n.t. & n.t. & n.t. & & 0.97 & & n.t. & n.t. & n.t. & 0.24 & {$[69]$} \\
\hline norbatzelladine A (44) & n.t. & n.t. & n.t. & n.t. & n.t. & n.t. & n.t. & n.t. & n.t. & n.t. & n.t. & $0.2 *$ & n.t. & n.t. & n.t. & n.t. & {$[68]$} \\
\hline norbatzelladine L (45) & n.t. & n.t. & n.t. & n.t. & n.t. & n.t. & n.t. & n.t. & n.t. & n.t. & n.t. & $0.3^{*}$ & $1.3^{*}$ & n.t. & $4.4^{*}$ & n.t. & {$[68,70]$} \\
\hline dinorbatzelladine A (46) & n.t. & n.t. & n.t. & n.t. & n.t. & n.t. & n.t. & n.t. & n.t. & n.t. & n.t. & $1.7^{*}$ & n.t. & n.t. & n.t. & n.t. & {$[68]$} \\
\hline dinordehydrobatzelladine B (48) & n.t. & n.t. & n.t. & n.t. & n.t. & n.t. & n.t. & n.t. & n.t. & n.t. & n.t. & $0.6^{*}$ & n.t. & n.t. & n.t. & n.t. & {$[68]$} \\
\hline dihomodehydrobatzelladine C (49) & n.t. & n.t. & n.t. & n.t. & n.t. & n.t. & n.t. & n.t. & n.t. & n.t. & n.t. & $2.3^{*}$ & n.t. & n.t. & n.t. & n.t. & [68] \\
\hline
\end{tabular}

S. aureus, Staphyloccocus aureus; MRSA, Methicilline resistant Staphyloccocus aureus; P. aeruginosa, Pseudomonas aeruginosa; M. tuberculosis, Mycobacterium tuberculosis; M. intracellulare, Mycobacterium intracellulare; V. angillarum, Vibrio angillarum; C. albicans, Candida albicans; A. fumigatus, Aspergillus fumigatus; P. falciparum, Plasmodium falciparum; L. infatum, Leishmania infatum; L. donovani, Leishmania donovani; T. cruzi, Trypanosoma cruzi; T. brucei brucei, Trypanosoma brucei brucei; AC, active concentration; NA, not active according to the authors; n.t., not tested; * converted from $\mu \mathrm{M}$ to $\mu \mathrm{g} / \mathrm{mL} ; \mathrm{a}, 9-10 \mathrm{~mm} / 50 \mu \mathrm{g}$ 
Table 9. TGA antitumor activities (values are expressed in $\mu \mathrm{g} / \mathrm{mL}$ unless specified).

\begin{tabular}{|c|c|c|c|c|c|c|c|c|c|c|c|c|c|c|c|c|c|}
\hline & & \multirow{2}{*}{$\begin{array}{l}\text { Prostate } \\
\text { DU-145 }\end{array}$} & \multirow{2}{*}{$\begin{array}{l}\text { Ovary } \\
\text { IGROV }\end{array}$} & \multicolumn{2}{|c|}{ Breast } & \multirow{2}{*}{$\begin{array}{l}\text { Melanoma } \\
\text { SK-MEL-28 }\end{array}$} & \multirow{2}{*}{$\begin{array}{c}\text { Lung } \\
\text { NSCL A549 }\end{array}$} & \multicolumn{3}{|c|}{ Leukemia } & \multicolumn{2}{|l|}{ Pancreas } & \multicolumn{2}{|c|}{ Colon } & \multirow{2}{*}{\multicolumn{2}{|c|}{\begin{tabular}{|cc} 
& Cervix \\
LOVO-DOX & HeLa \\
\end{tabular}}} & \multirow{2}{*}{ Ref } \\
\hline & & & & SK-BR3 & MDA-MB-231 & & & L-562 & HL-60 & THP-1 & PANCL & HT29 & HCT-16 & LOVO & & & \\
\hline \multirow{3}{*}{ ptilomycalin A (1) } & $\mathrm{GI}_{50}$ & 0.05 & 0.04 & 0.07 & n.t. & 0.03 & 0.08 & 0.04 & n.t. & n.t. & 0.04 & 0.03 & n.t. & 0.05 & 0.05 & 0.04 & \multirow{3}{*}{ [73] } \\
\hline & TGI & 1.22 & 1.74 & 0.54 & n.t. & 0.11 & 1.23 & 1.33 & n.t. & n.t. & 0.99 & 0.19 & n.t. & 2.14 & 2.04 & 0.22 & \\
\hline & $\mathrm{LC}_{50}$ & 5.21 & n.t. & n.t. & n.t. & 0.98 & 9.79 & 9.72 & n.t. & n.t. & 0.98 & 5.37 & n.t. & 9.79 & 8.48 & 3.21 & \\
\hline \multirow{3}{*}{ crambescidin $800(2)$} & $\mathrm{GI}_{50}$ & 0.19 & 0.05 & 0.16 & n.t. & 0.04 & 0.11 & 0.02 & n.t. & n.t. & 0.04 & 0.04 & n.t. & 0.08 & 0.08 & 0.05 & \multirow{3}{*}{ [73] } \\
\hline & TGI & 1.38 & 2.50 & 0.56 & n.t. & 0.11 & 1.36 & 0.06 & n.t. & n.t. & 1.53 & 0.23 & n.t. & 2.29 & 2.02 & 0.21 & \\
\hline & $\mathrm{LC}_{50}$ & 7.01 & n.t. & n.t. & n.t. & 1.70 & 9.68 & 6.73 & n.t. & n.t. & 8.66 & 5.75 & n.t. & 8.97 & 8.50 & 1.58 & \\
\hline \multirow{3}{*}{ crambescidin 816 (3) } & $\mathrm{GI}_{50}$ & n.t. & n.t. & n.t. & n.t. & n.t. & n.t. & n.t. & n.t. & n.t. & n.t. & n.t. & \multirow{3}{*}{$\begin{array}{l}\mathrm{IC}_{50} \\
0.24\end{array}$} & n.t. & n.t. & n.t. & \multirow{3}{*}{52} \\
\hline & TGI & n.t. & n.t. & n.t. & n.t. & n.t. & n.t. & n.t. & n.t. & n.t. & n.t. & n.t. & & n.t. & n.t. & n.t. & \\
\hline & $\mathrm{LC}_{50}$ & n.t. & n.t. & n.t. & n.t. & n.t. & n.t. & n.t. & n.t. & n.t. & n.t. & n.t. & & n.t. & n.t. & n.t. & \\
\hline \multirow{3}{*}{ monanchocidin A (18) } & $\mathrm{GI}_{50}$ & n.t. & n.t. & n.t. & n.t. & n.t. & n.t. & n.t. & n.t. & \multirow{3}{*}{$\begin{array}{l}\mathrm{IC}_{50} \\
4.4^{*}\end{array}$} & n.t. & n.t. & n.t. & n.t. & n.t. & \multirow{3}{*}{$\mathrm{IC}_{50} 10.1 *$} & \multirow{3}{*}{ [61] } \\
\hline & TGI & n.t. & n.t. & n.t. & n.t. & n.t. & n.t. & n.t. & n.t. & & n.t. & n.t. & n.t. & n.t. & n.t. & & \\
\hline & $\mathrm{LC}_{50}$ & n.t. & n.t. & n.t. & n.t. & n.t. & n.t. & n.t. & n.t. & & n.t. & n.t. & n.t. & n.t. & n.t. & & \\
\hline \multirow{3}{*}{ monanchocidin B (19) } & $\mathrm{GI}_{50}$ & n.t. & n.t. & n.t. & n.t. & n.t. & n.t. & n.t. & \multirow{3}{*}{$\begin{array}{l}\mathrm{IC}_{50} \\
0.17^{*}\end{array}$} & n.t. & n.t. & n.t. & n.t. & n.t. & n.t. & n.t. & \multirow{3}{*}{ [62] } \\
\hline & TGI & n.t. & n.t. & n.t. & n.t. & n.t. & n.t. & n.t. & & n.t. & n.t. & n.t. & n.t. & n.t. & n.t. & n.t. & \\
\hline & $\mathrm{LC}_{50}$ & n.t. & n.t. & n.t. & n.t. & n.t. & n.t. & n.t. & & n.t. & n.t. & n.t. & n.t. & n.t. & n.t. & n.t. & \\
\hline & $\mathrm{GI}_{50}$ & n.t. & n.t. & n.t. & n.t. & n.t. & n.t. & n.t. & & n.t. & n.t. & n.t. & n.t. & n.t. & n.t. & n.t. & \\
\hline monanchocidin C (20) & TGI & n.t. & n.t. & n.t. & n.t. & n.t. & n.t. & n.t. & $0.09 *$ & n.t. & n.t. & n.t. & n.t. & n.t. & n.t. & n.t. & [62] \\
\hline & $\mathrm{LC}_{50}$ & n.t. & n.t. & n.t. & n.t. & n.t. & n.t. & n.t. & & n.t. & n.t. & n.t. & n.t. & n.t. & n.t. & n.t. & \\
\hline & $\mathrm{GI}_{50}$ & n.t. & n.t. & n.t. & n.t. & n.t. & n.t. & n.t. & & n.t. & n.t. & n.t. & n.t. & n.t. & n.t. & n.t. & \\
\hline monanchocidin D (21) & TGI & n.t. & n.t. & n.t. & n.t. & n.t. & n.t. & n.t. & $0.69 *$ & n.t. & n.t. & n.t. & n.t. & n.t. & n.t. & n.t. & [62] \\
\hline & $\mathrm{LC}_{50}$ & n.t. & n.t. & n.t. & n.t. & n.t. & n.t. & n.t. & & n.t. & n.t. & n.t. & n.t. & n.t. & n.t. & n.t. & \\
\hline & $\mathrm{GI}_{50}$ & n.t. & n.t. & n.t. & n.t. & n.t. & n.t. & n.t. & & n.t. & n.t. & n.t. & n.t. & n.t. & n.t. & n.t. & \\
\hline monanchocidin E (22) & TGI & n.t. & n.t. & n.t. & n.t. & n.t. & n.t. & n.t. & $\begin{array}{l}15_{50} \\
0.55 *\end{array}$ & n.t. & n.t. & n.t. & n.t. & n.t. & n.t. & n.t. & [62] \\
\hline & $\mathrm{LC}_{50}$ & n.t. & n.t. & n.t. & n.t. & n.t. & n.t. & n.t. & & n.t. & n.t. & n.t. & n.t. & n.t. & n.t. & n.t. & \\
\hline & $\mathrm{GI}_{50}$ & n.t. & n.t. & n.t. & n.t. & n.t. & n.t. & n.t. & & n.t. & n.t. & n.t. & n.t. & n.t. & n.t. & n.t. & \\
\hline monanchomycalin A (23) & TGI & n.t. & n.t. & n.t. & n.t. & n.t. & n.t. & n.t. & 0.10 * & n.t. & n.t. & n.t. & n.t. & n.t. & n.t. & n.t. & [63] \\
\hline & $\mathrm{LC}_{50}$ & n.t. & n.t. & n.t. & n.t. & n.t. & n.t. & n.t. & & n.t. & n.t. & n.t. & n.t. & n.t. & n.t. & n.t. & \\
\hline & $\mathrm{GI}_{50}$ & n.t. & n.t. & n.t. & n.t. & n.t. & n.t. & n.t. & & n.t. & n.t. & n.t. & n.t. & n.t. & n.t. & n.t. & \\
\hline monanchomycalin B (24) & TGI & n.t. & n.t. & n.t. & n.t. & n.t. & n.t. & n.t. & 0.11 * & n.t. & n.t. & n.t. & n.t. & n.t. & n.t. & n.t. & [63] \\
\hline & $\mathrm{LC}_{50}$ & n.t. & n.t. & n.t. & n.t. & n.t. & n.t. & n.t. & & n.t. & n.t. & n.t. & n.t. & n.t. & n.t. & n.t. & \\
\hline
\end{tabular}


Table 9. Cont.

\begin{tabular}{|c|c|c|c|c|c|c|c|c|c|c|c|c|c|c|c|c|c|}
\hline & & Prostate & Ovary & & Breast & Melanoma & Lung & & eukemia & & Pancreas & & & Colon & & Cervix & Ref \\
\hline & & DU-145 & IGROV & SK-BR3 & MDA-MB-231 & SK-MEL-28 & NSCL A549 & L-562 & HL-60 & THP-1 & PANCL & HT29 & HCT-16 & LOVO & LOVO-DOX & HeLa & (1) \\
\hline \multirow{3}{*}{ batzelladine C (28) } & $\mathrm{GI}_{50}$ & 0.68 & 0.81 & 0.66 & n.t. & 1.45 & 1.40 & 0.62 & n.t. & n.t. & 0.55 & 0.65 & n.t. & 2.06 & 2.25 & 0.70 & \multirow{3}{*}{ [73] } \\
\hline & TGI & 2.27 & 3.43 & 2.89 & n.t. & 3.67 & 3.42 & 3.01 & n.t. & n.t. & 2.03 & 2.16 & n.t. & 4.37 & 4.72 & 2.22 & \\
\hline & $\mathrm{LC}_{50}$ & 0.69 & n.t. & n.t. & n.t. & 9.24 & 8.31 & n.t. & n.t. & n.t. & 7.14 & 6.70 & n.t. & 9.29 & 0.99 & 6.50 & \\
\hline \multirow{3}{*}{ dehydrobatzelladine C (35) } & $\mathrm{GI}_{50}$ & 0.46 & 0.73 & 0.23 & n.t. & 0.89 & 1.19 & 0.48 & n.t. & n.t. & 0.43 & 0.48 & n.t. & 1.60 & 2.07 & 0.48 & \multirow{3}{*}{ [73] } \\
\hline & TGI & 1.91 & 4.17 & 1.14 & n.t. & 3.48 & 3.24 & 2.42 & n.t. & n.t. & 1.83 & 1.77 & n.t. & 3.68 & 4.48 & 1.52 & \\
\hline & $\mathrm{LC}_{50}$ & 7.15 & n.t. & n.t. & n.t. & n.t. & 8.81 & n.t. & n.t. & n.t. & 8.66 & 7.50 & n.t. & 8.47 & 9.69 & 5.45 & \\
\hline \multirow{3}{*}{ batzelladine L (38) } & $\mathrm{GI}_{50}$ & 0.44 & 0.52 & 0.23 & n.t. & 0.88 & 1.30 & n.t. & n.t. & n.t. & 0.34 & 4.96 & n.t. & 1.09 & n.t. & 0.38 & \multirow{3}{*}{ [73] } \\
\hline & TGI & 1.39 & 1.74 & 0.56 & n.t. & 2.18 & 9.99 & n.t. & n.t. & n.t. & 1.33 & n.t. & n.t. & 2.41 & n.t. & 1.16 & \\
\hline & $\mathrm{LC}_{50}$ & 3.78 & 5.01 & 2.10 & n.t. & 4.95 & n.t. & n.t. & n.t. & n.t. & 4.38 & n.t. & n.t. & 5.36 & n.t. & 3.58 & \\
\hline \multirow{3}{*}{ batzelladine M (39) } & $\mathrm{GI}_{50}$ & 1.77 & 2.28 & 1.12 & n.t. & 1.18 & 3.80 & n.t. & n.t. & n.t. & 1.22 & 3.56 & n.t. & 1.99 & n.t. & 1.64 & \multirow{3}{*}{ [73] } \\
\hline & TGI & 3.44 & 5.08 & 2.51 & n.t. & 4.66 & n.t. & 0.00 & n.t. & n.t. & 3.58 & n.t. & n.t. & 3.56 & n.t. & 3.05 & \\
\hline & $\mathrm{LC}_{50}$ & 6.66 & n.t. & 5.59 & n.t. & n.t. & n.t. & 0.00 & n.t. & n.t. & n.t. & n.t. & n.t. & 6.37 & n.t. & 5.68 & \\
\hline \multirow{3}{*}{ batzelladine $\mathrm{N}(\mathbf{4 0})$} & $\mathrm{GI}_{50}$ & 1.39 & 1.78 & 1.12 & n.t. & 1.47 & 1.94 & 0.66 & n.t. & n.t. & 1.37 & 1.31 & n.t. & 1.96 & 4.42 & 0.59 & \multirow{3}{*}{ [73] } \\
\hline & TGI & 3.12 & 4.97 & 3.84 & n.t. & 3.41 & 4.29 & 3.27 & n.t. & n.t. & 3.50 & 3.11 & n.t. & 4.16 & n.t. & 1.80 & \\
\hline & $\mathrm{LC}_{50}$ & 7.04 & n.t. & n.t. & n.t. & 7.97 & 9.47 & n.t. & n.t. & n.t. & 8.97 & 7.35 & n.t. & 8.85 & n.t. & 5.13 & \\
\hline \multirow{3}{*}{ clathriadic acid (41) } & $\mathrm{GI}_{50}$ & n.t. & n.t. & n.t. & 13.5 & n.t. & $>30$ & n.t. & n.t. & n.t. & n.t. & $>30$ & n.t. & n.t. & n.t. & n.t. & \multirow{3}{*}{ [68] } \\
\hline & TGI & n.t. & n.t. & n.t. & $>30$ & n.t. & $>30$ & n.t. & n.t. & n.t. & n.t. & $>30$ & n.t. & n.t. & n.t. & n.t. & \\
\hline & $\mathrm{LC}_{50}$ & n.t. & n.t. & n.t. & $>30$ & n.t. & $>30$ & n.t. & n.t. & n.t. & n.t. & $>30$ & n.t. & n.t. & n.t. & n.t. & \\
\hline \multirow{3}{*}{ norbatzelladine A (44) } & $\mathrm{GI}_{50}$ & n.t. & n.t. & n.t. & 3.8 & n.t. & 2.1 & n.t. & n.t. & n.t. & n.t. & 1.6 & n.t. & \multirow{3}{*}{$\mathrm{TC}_{50} 4.7 \mu \mathrm{M}$} & n.t. & n.t. & \multirow{3}{*}{ [68] } \\
\hline & TGI & n.t. & n.t. & n.t. & 6.4 & n.t. & 4.6 & n.t. & n.t. & n.t. & n.t. & 3.2 & n.t. & & n.t. & n.t. & \\
\hline & $\mathrm{LC}_{50}$ & n.t. & n.t. & n.t. & 11.4 & n.t. & 8.6 & n.t. & n.t. & n.t. & n.t. & 5.7 & n.t. & & n.t. & n.t. & \\
\hline \multirow{3}{*}{ norbatzelladine L (45) } & $\mathrm{GI}_{50}$ & n.t. & n.t. & n.t. & 0.7 & n.t. & 1.1 & n.t. & n.t. & n.t. & n.t. & 1.9 & n.t. & n.t. & n.t. & n.t. & \multirow{3}{*}{ [68] } \\
\hline & TGI & n.t. & n.t. & n.t. & 1.9 & n.t. & 2.1 & n.t. & n.t. & n.t. & n.t. & 4.2 & n.t. & n.t. & n.t. & n.t. & \\
\hline & $\mathrm{LC}_{50}$ & n.t. & n.t. & n.t. & 4.8 & n.t. & 4.2 & n.t. & n.t. & n.t. & n.t. & 7.6 & n.t. & n.t. & n.t. & n.t. & \\
\hline \multirow{3}{*}{ dinorbatzelladine A (46) } & $\mathrm{GI}_{50}$ & n.t. & n.t. & n.t. & 3.0 & n.t. & 1.9 & n.t. & n.t. & n.t. & n.t. & 1.9 & n.t. & n.t. & n.t. & n.t. & \multirow{3}{*}{ [68] } \\
\hline & TGI & n.t. & n.t. & n.t. & 3.8 & n.t. & 4.2 & n.t. & n.t. & n.t. & n.t. & 4.2 & n.t. & n.t. & n.t. & n.t. & \\
\hline & $\mathrm{LC}_{50}$ & n.t. & n.t. & n.t. & 5.4 & n.t. & 7.6 & n.t. & n.t. & n.t. & n.t. & 7.6 & n.t. & n.t. & n.t. & n.t. & \\
\hline \multirow{3}{*}{ dinordehydro-batzelladine B (48) } & $\mathrm{GI}_{50}$ & n.t. & n.t. & n.t. & n.t. & n.t. & 7.9 & n.t. & n.t. & n.t. & n.t. & 6.2 & n.t. & n.t. & n.t. & n.t. & \multirow{3}{*}{ [68] } \\
\hline & TGI & n.t. & n.t. & n.t. & n.t. & n.t. & $>14$ & n.t. & n.t. & n.t. & n.t. & $>14$ & n.t. & n.t. & n.t. & n.t. & \\
\hline & $\mathrm{LC}_{50}$ & n.t. & n.t. & n.t. & n.t. & n.t. & $>14$ & n.t. & n.t. & n.t. & n.t. & $>14$ & n.t. & n.t. & n.t. & n.t. & \\
\hline \multirow{3}{*}{ dihomodehydro-batzelladine C (49) } & $\mathrm{GI}_{50}$ & n.t. & n.t. & n.t. & 6.1 & n.t. & $>30$ & n.t. & n.t. & n.t. & n.t. & $>30$ & n.t. & n.t. & n.t. & n.t. & \multirow{3}{*}{ [68] } \\
\hline & TGI & n.t. & n.t. & n.t. & 9.8 & n.t. & $>30$ & n.t. & n.t. & n.t. & n.t. & $>30$ & n.t. & n.t. & n.t. & n.t. & \\
\hline & $\mathrm{LC}_{50}$ & n.t. & n.t. & n.t. & 15.6 & n.t. & $>30$ & n.t. & n.t. & n.t. & n.t. & $>30$ & n.t. & n.t. & n.t. & n.t. & \\
\hline
\end{tabular}


Ptilomycalin A (1) is once again the most active TGA tested as its half maximal growth inhibition values $\left(\mathrm{GI}_{50}\right)$ are always below $0.1 \mu \mathrm{g} / \mathrm{mL}$ on all the cell lines tested [73]. Crambescidin 800 (2) shows similar activities [73]. Compared to TGA class 3, TGA class 2 is less active, although batzelladine $\mathrm{C}$ (28) and L (38) and dehydrobatzelladine C (35), in general, exhibited a GI ${ }_{50}$ below $1 \mu \mathrm{g} / \mathrm{mL}$ [73]. Finally, crambescidin 816 (3) was shown to inhibit cell migration by altering the cytoskeleton dynamics and induced cell death by apoptosis $[75,78]$.

In summary, both TGA class 2 and 3 have been tested against viruses, microbes, and several cancer cell lines. The wide-ranging biological activity of this class of natural products can be in part attributed to the cationic nature of the guanidinium functional group that can participate in a large number of non-covalent molecular interactions [77]. In general, TGA from class 3 exhibited better activities compared to TGA from class 2 [73]. Within TGA class 3, ptilomycalin A (1) and crambescidin 800 (2) showed similar activities in all assays, suggesting that the hydroxyl group of the right-handed portion in crambescidin 800 (2) did not affect the bioactivity. Nevertheless, 16 $\beta$-hydroxycrambescidin 359 (16) did not show any significant antimicrobial activity, suggesting that the hydroxyl group, located on the pentacycle at C-16, diminished the activity [73]. Further studies are needed to confirm this hypothesis. This could be assessed by evaluating the inhibitory activities of crambescidins 816 (3), 830 (4) and 844 (5), as they carry the same hydroxyl moiety as crambescidin 800 (2) and another hydroxyl located in the pentacycle at C-13. In parallel, several batzelladines have been reported to disrupt protein-protein interactions. Elucidation of the mechanism by which protein-protein interactions are modulated by these molecules is of great interest, since protein-protein associations are important in all the aspects of cell biochemistry. Moreover, small molecules that influence protein-protein association would be new biological tools and potential therapeutic agents. In particular, batzelladines or their derivatives may prove to be applicable for AIDS treatment. Batzelladines A-E (26-30) block interaction between the surface of the HIV envelope glycoprotein gp120 and the extracellular domains of human CD4 receptor protein [66]. A subset of batzelladines exhibited also potential immunosuppressive activity as they induce dissociation of the complex between the protein kinase p56 $6^{\mathrm{lck}}$ and CD4 [67]. Synthetic derivatives of batzelladines were reported to disrupt Nef-p53, Nef-actin, and Nef-p56 lck interactions [77]. Bewley et al. tested a series of 28 synthetic batzelladine-like GA analogues on HIV-1 cell fusion assay, to find structure-activity relationships [76]. According to this study, the greater the rigidity of the molecule, the less biologically active it is. Moreover, they have shown that the most active compounds tested were compounds which contain two tricyclic guanidine moieties connected by an alkyl ester linkage including eight heavy atoms, such as batzelladines $F$ (31) and G (32). Batzelladines biological properties could be dramatically affected by the ester side chains. For example, batzelladine A (26) inhibits the binding of HIV glycoprotein gp120 to CD4 receptors, whereas batzelladine D (29) has no known biological activity [77].

Finally, several derivatives that do not feature an ester side chain may still exhibit interesting biological properties such as the antibacterial and antimalarial activities of merobatzelladines A (42) and B (43) [69].

\section{Conclusions}

Several batzelladine- and crambescidin-like guanidine alkaloids have been isolated from Poecilosclerida marine sponges. Their biosynthesis, or the biosynthesis of their precursors, may involve symbiotic microorganisms [79]. This class of natural products is structurally unique as all the derivatives are constituted by a tricyclic guanidinium ring system, to which are appended different substituents. This significant structural diversity has led to wide-ranging biological properties with mainly antiviral, antimicrobial (including antifungal, antibacterial, anti-yeast, and antiparasitic), and antitumor activities. In addition to the biomimetic strategy, a number of groups completed the total synthesis of several of these alkaloids by developing new synthetic methodologies. Although there are many efficient and stereoselective synthetic routes towards this class of natural products, there is not yet one method that would allow entry into all of the cores of this family. Nonetheless, a number of these 
syntheses have enabled the establishment of their relative and absolute stereochemical configurations. In conclusion, several of these alkaloids and their synthetic analogs were prepared on a large enough scale to allow further biological testing, including few structure-activity relationship studies. Ongoing studies may provide us with further clues regarding this class of Marine Natural Products.

Acknowledgments: We thank J. Pattinson and D. Coaten for their kind reading of this manuscript. E. Sfecci is the recipient of a thesis grant from the "Conseil Régional Provence Alpes Côte d'azur". M. Mehiri's research is supported by the French program ENVI-Med "MEDIBIO", the ANR/Investissements d'Avenir program via the OCEANOMICs project (grant \#ANR-11-BTBR-0008), and the H2020 European program via the EMBRIC project.

Author Contributions: All the authors wrote, read, and approved the final version of the manuscript.

Conflicts of Interest: The authors declare no conflict of interest.

\section{Abbreviations}

The following abbreviations are used in this manuscript:

$\begin{array}{ll}\text { A.m. } & \text { Antimicrobial activity } \\ \text { A.v. } & \text { Antiviral activity } \\ \text { A.t. } & \text { Antitumor activity } \\ \text { COSY } & \text { Correlation Spectroscopy } \\ \text { EC }_{50} & \text { half maximal Effective Concentration } \\ \text { GA } & \text { Guanidine Alkaloids } \\ \text { GI }_{50} & \text { half maximal Growth Inhibition } \\ \text { gp120 } & \text { glycoprotein 120 } \\ \text { HBV } & \text { Human hepatitis B virus } \\ \text { HIV-1 } & \text { Human Immunodeficiency Virus 1 } \\ \text { HSV-1 } & \text { Herpes simplex Virus 1 } \\ \text { IC } 50 & \text { half maximal Inhibitory Concentration } \\ \text { LC } 50 & \text { half maximal Lethal Concentration } \\ \text { MIC } & \text { Minimum Inhibitory Concentration } \\ \text { MS } & \text { Mass Spectrometry } \\ \text { NMR } & \text { Nuclear Magnetic Resonance } \\ \text { n.t. } & \text { Not tested } \\ \text { PBMC } & \text { Peripheral Blood Mononuclear Cells } \\ \text { SM } & \text { Secondary Metabolites } \\ \text { TC } & \text { half maximal Toxic Concentration } \\ \text { TGA } & \text { Triazaacenaphthylene Guanidine Alkaloids } \\ \text { TGI } & \text { Total Growth Inhibition concentration }\end{array}$

\section{References}

1. Nijampatnam, B.; Dutta, S.; Velu, S.E. Recent advances in isolation, synthesis, and evaluation of bioactivities of bispyrroloquinone alkaloids of marine origin. Chin. J. Nat. Med. 2015, 13, 561-577. [CrossRef]

2. Gul, W.; Hamann, M.T. Indole alkaloid marine natural products: An established source of cancer drug leads with considerable promise for the control of parasitic, neurological and other diseases. Life Sci. 2005, 78, 442-453. [CrossRef] [PubMed]

3. Forte, B.; Malgesini, B.; Piutti, C.; Quartieri, F.; Scolaro, A.; Papeo, G. A submarine journey: The pyrrole-imidazole alkaloids. Mar. Drugs 2009, 7, 705-753. [CrossRef] [PubMed]

4. Weinreb, S.M. Some recent advances in the synthesis of polycyclic imidazole-containing marine natural products. Nat. Prod. Rep. 2007, 24, 931-948. [CrossRef] [PubMed]

5. Berlinck, R.G.S. Natural guanidine derivatives. Nat. Prod. Rep. 2002, 19, 617-649. [CrossRef] [PubMed]

6. Berlinck, R.G.S.; Burtoloso, A.C.; Kossuga, M.H. The chemistry and biology of organic guanidine derivatives. Nat. Prod. Rep. 2008, 25, 919-954. [CrossRef] [PubMed] 
7. Berlinck, R.G.S.; Burtoloso, A.C.; Trindade-Silva, A.E.; Romminger, S.; Morais, R.P.; Bandeira, K.; Mizuno, C.M. The chemistry and biology of organic guanidine derivatives. Nat. Prod. Rep. 2010, 27, 1871-1907. [CrossRef] [PubMed]

8. Berlinck, R.G.S.; Kossuga, M.H. Natural guanidine derivatives. Nat. Prod. Rep. 2005, 22, 516-550. [CrossRef] [PubMed]

9. Berlinck, R.G.S. Natural guanidine derivatives. Nat. Prod. Rep. 1999, 16, 339-365. [CrossRef]

10. Faulkner, J.D. Marine natural products. Nat. Prod. Rep. 2001, 18, 1-49. [CrossRef] [PubMed]

11. Blunt, J.W.; Copp, B.R.; Keyzers, R.A.; Munro, M.H.; Prinsep, M.R. Marine natural products. Nat. Prod. Rep. 2015, 32, 116-211. [CrossRef] [PubMed]

12. Blunt, J.W.; Copp, B.R.; Hu, W.-P.; Munro, M.H.G.; Northcote, P.T.; Prinsep, M.R. Marine natural products. Nat. Prod. Rep. 2007, 24, 31-86. [CrossRef] [PubMed]

13. Blunt, J.W.; Copp, B.R.; Hu, W.-P.; Munro, M.H.G.; Northcote, P.T.; Prinsep, M.R. Marine natural products. Nat. Prod. Rep. 2008, 25, 35-94. [CrossRef] [PubMed]

14. Blunt, J.W.; Copp, B.R.; Hu, W.-P.; Munro, M.H.G.; Northcote, P.T.; Prinsep, M.R. Marine natural products. Nat. Prod. Rep. 2009, 26, 170-244. [CrossRef] [PubMed]

15. Blunt, J.W.; Copp, B.R.; Munro, M.H.G.; Northcote, P.T.; Prinsep, M.R. Marine natural products. Nat. Prod. Rep. 2010, 27, 165-237. [CrossRef] [PubMed]

16. Blunt, J.W.; Copp, B.R.; Munro, M.H.G.; Northcote, P.T.; Prinsep, M.R. Marine natural products. Nat. Prod. Rep. 2011, 28, 196-268. [CrossRef] [PubMed]

17. Blunt, J.W.; Copp, B.R.; Keyzers, R.A.; Munro, M.H.G.; Prinsep, M.R. Marine natural products. Nat. Prod. Rep. 2012, 29, 144-222. [CrossRef] [PubMed]

18. Blunt, J.W.; Copp, B.R.; Keyzers, R.A.; Munro, M.H.G.; Prinsep, M.R. Marine natural products. Nat. Prod. Rep. 2013, 30, 237-323. [CrossRef] [PubMed]

19. Blunt, J.W.; Copp, B.R.; Keyzers, R.A.; Munro, M.H.G.; Prinsep, M.R. Marine natural products. Nat. Prod. Rep. 2014, 31, 160-258. [CrossRef] [PubMed]

20. Berlinck, R.G.S.; Trindade-Silva, A.E.; Santos, M.F. The chemistry and biology of organic guanidine derivatives. Nat. Prod. Rep. 2012, 29, 1382-1406. [CrossRef] [PubMed]

21. Snider, B.B.; Shi, Z. Biomimetic synthesis of the central tricyclic portion of ptilomycalin A. Tetrahedron Lett. 1993, 34, 2099-2102. [CrossRef]

22. Rao, A.V.R.; Gurjar, M.K.; Vasudevan, J. An enantiospecific synthesis of the tricyclic guanidine segment of the anti-HIV marine alkaloid batzelladine A. J. Chem. Soc. Chem. Commun. 1995, 13, 1369-1370. [CrossRef]

23. Louwrier, S.; Ostendorf, M.; Boom, A.; Hiemstra, H.; Speckamp, W.N. Studies towards the synthesis of (+)-ptilomycalin $\mathrm{A}$; stereoselective $\mathrm{N}$-acyliminium ion coupling reactions to enantiopure $\mathrm{C}-2$ substituted lactams. Tetrahedron 1996, 52, 2603-2628. [CrossRef]

24. Louwrier, S.; Ostendorf, M.; Tuynman, A.; Hiemstra, H. Studies towards the synthesis of guanidine alkaloids; synthesis of a tricyclic guanidine from succinimide. Tetrahedron Lett. 1996, 37, 905-908. [CrossRef]

25. Louwrier, S.; Tuynman, A.; Hiemstra, H. Synthesis of bicyclic guanidines from pyrrolidin-2-one. Tetrahedron 1996, 52, 2629-2646. [CrossRef]

26. Murphy, P.J.; Lloyd Williams, H.; Hibbs, D.E.; Hursthouse, M.B.; Malik, A.K.M. Biomimetic model studies towards ptilomycalin A. Tetrahedron 1996, 52, 8315-8332. [CrossRef]

27. Snider, B.B.; Chen, J.; Patil, A.D.; Freyer, A.J. Synthesis of the tricyclic portions of batzelladines A, B and D. Revision of the stereochemistry of batzelladines A and D. Tetrahedron Lett. 1996, 37, 6977-6980. [CrossRef]

28. Black, G.P.; Murphy, P.J.; Walshe, N.D.A. A short synthetic route to the tricyclic guanidinium core of the batzelladine alkaloids. Tetrahedron 1998, 54, 9481-9488. [CrossRef]

29. Black, G.P.; Murphy, P.J.; Thornhill, A.J.; Walshe, N.D.A.; Zanetti, C. Synthesis of the left hand unit of batzelladine F; revision of the reported relative stereochemistry. Tetrahedron 1999, 55, 6547-6554. [CrossRef]

30. Snider, B.B.; Busuyek, M.V. Revision of the stereochemistry of batzelladine F. Approaches to the tricyclic hydroxyguanidine moiety of batzelladines G, H, and I. J. Nat. Prod. 1999, 62, 1707-1711. [CrossRef] [PubMed]

31. Coffey, D.S.; McDonald, A.I.; Overman, L.E.; Rabinowitz, M.H.; Renhowe, P.A. A practical entry to the crambescidin family of guanidine alkaloids. Enantioselective total syntheses of ptilomycalin A, crambescidin 657 and its methyl ester (neofolitispates 2), and crambescidin 800. J. Am. Chem. Soc. 2000, 122, 4893-4903. [CrossRef] 
32. Elliott, M.C.; Long, M.S. Studies towards the total synthesis of batzelladine A. Org. Biomol. Chem 2004, 2, 2003-2011. [CrossRef] [PubMed]

33. Aron, Z.D.; Overman, L.E. Total synthesis and properties of the crambescidin core zwitterionic acid and crambescidin 359. J. Am. Chem. Soc. 2005, 127, 3380-3390. [CrossRef] [PubMed]

34. Shi, Y.; Pierce, J.G. Synthesis of the 5,6-dihydroxymorpholin-3-one fragment of monanchocidin A. Org. Lett. 2015, 17, 968-971. [CrossRef] [PubMed]

35. Snider, B.B.; Chen, J. Synthesis of batzelladine E and its E isomer. Tetrahedron Lett. 1998, 39, 5697-5700. [CrossRef]

36. Coffey, D.S.; McDonald, A.I.; Overman, L.E.; Stappenbeck, F. Enantioselective total synthesis of 13,14,15-isocrambescidin 800. J. Am. Chem. Soc. 1999, 121, 6944-6945. [CrossRef]

37. Cohen, F.; Overman, L.E.; Ly Sakata, S.K. Asymmetric total synthesis of batzelladine D. Org. Lett. 1999, 1, 2169-2172. [CrossRef] [PubMed]

38. Franklin, A.S.; Ly, S.K.; Mackin, G.H.; Overman, L.E.; Shaka, A.J. Application of the tethered biginelli reaction for enantioselective synthesis of batzelladine alkaloids. Absolute configuration of the tricyclic guanidine portion of batzelladine B. J. Org. Chem. 1999, 64, 1512-1519. [CrossRef] [PubMed]

39. Cohen, F.; Overman, L.E. Enantioselective total synthesis of batzelladine F: Structural revision and stereochemical definition. J. Am. Chem. Soc. 2001, 123, 10782-10783. [CrossRef] [PubMed]

40. Ishiwata, T.; Hino, T.; Koshino, H.; Hashimoto, Y.; Nakata, T.; Nagasawa, K. Total synthesis of batzelladine D. Org. Lett. 2002, 4, 2921-2924. [CrossRef] [PubMed]

41. Nagasawa, K.; Hashimoto, Y. Synthesis of marine guanidine alkaloids and their application as chemical/biological tools. Chem. Rec. 2003, 3, 201-211. [CrossRef] [PubMed]

42. Aron, Z.D.; Overman, L.E. The tethered biginelli condensation in natural product synthesis. Chem. Commun. 2004, 3, 253-265. [CrossRef] [PubMed]

43. Collins, S.K.; McDonald, A.I.; Overman, L.E.; Ho Rhee, Y. Enantioselective total synthesis of (-)-dehydrobatzelladine C. Org. Lett. 2004, 6, 1253-1255. [CrossRef] [PubMed]

44. Arnold, M.A.; Duron, S.G.; Gin, D.Y. Diastereoselective [4+2] annulation of vinyl carbodiimides with $N$-alkyl imines. Asymmetric synthetic access to the batzelladine alkaloids. J. Am. Chem. Soc. 2005, 127, 6924-6925. [CrossRef] [PubMed]

45. Overman, L.E.; Ho Rhee, Y. Total synthesis of (-)-crambidine and definition of the relative configuration of its unique tetracyclic guanidinium core. J. Am. Chem. Soc. 2005, 125, 15652-15658. [CrossRef] [PubMed]

46. Shimokawa, J.; Ishiwata, T.; Shirai, K.; Koshino, H.; Tanatani, A.; Nakata, T.; Hashimoto, Y.; Nagasawa, K. Total synthesis of (+)-batzelladine $\mathrm{A}$ and (-)-batzelladine $\mathrm{D}$, and identification of their target protein. Chemistry 2005, 11, 6878-6888. [CrossRef] [PubMed]

47. Evans, P.A.; Qin, J.; Robinson, J.E.; Bazin, B. Enantioselective total synthesis of the polycyclic guanidine-containing marine alkaloid (-)-batzelladine D. Angew. Chem. 2007, 46, 7417-7419. [CrossRef] [PubMed]

48. Moore, C.G.; Murphy, P.J.; Williams, H.L.; McGown, A.T.; Smith, N.K. Synthetic studies towards ptilomycalin A: Total synthesis of crambescidin 359. Tetrahedron 2007, 63, 11771-11780. [CrossRef]

49. Perl, N.R.; Ide, N.D.; Prajapati, S.; Perfect, H.; Duro, S.G.; Gin, D.Y. Annulation of thioimidates and vinyl carbodiimides to prepare 2-aminopyrimidines, competent nucleophiles for intramolecular alkyne hydroamination. Synthesis of (-)-crambidine. J. Am. Chem. Soc. 2010, 132, 1802-1803. [CrossRef] [PubMed]

50. Babij, N.R.; Wolfe, J.P. Asymmetric total synthesis of (+)-merobatzelladine B. Angew. Chem. 2012, 51, 4128-4130. [CrossRef] [PubMed]

51. Kashman, Y.; Hirsh, S.; McConnell, O.J.; Ohtani, I.; Kusumi, T.; Kakisawa, H. Ptilomycalin A: A novel polycyclic guanidine alkaloid of marine origin. J. Am. Chem. Soc. 1989, 111, 8926-8928. [CrossRef]

52. Berlinck, R.G.S.; Braekman, J.C.; Daloze, D.; Bruno, I.; Riccio, R. Polycyclic guanidine alkaloids from the marine sponge Crambe crambe and Ca++ channel blocker activity of crambescidin 816. J. Nat. Prod. 1993, 56, 1007-1015. [CrossRef] [PubMed]

53. Braekman, J.C.; Daloze, D.; Tavares, R.; Hajdu, E.; Van Soest, R.W.M. Novel polycyclic guanidine alkaloids from two marine sponges of the genus Monanchora. J. Nat. Prod. 2000, 63, 193-196. [CrossRef] [PubMed]

54. Chang, L.; Whittaker, N.F.; Bewley, C.A. Crambescidin 826 and dehydrocrambine A: New polycyclic guanidine alkaloids from the marine sponge Monanchora sp. That inhibit HIV-1 fusion. J. Nat. Prod. 2003, 66, 1490-1494. [CrossRef] [PubMed] 
55. Jares-Erijman, E.A.; Sakai, R.; Rinehart, K.L. Crambescidins: New antiviral and cytotoxic compounds from the sponge Crambe crambe. J. Org. Chem. 1991, 56, 5712-5715. [CrossRef]

56. Jares-Erijman, E.A.; Ingrum, A.L.; Carney, J.R.; Rinehart, K.L.; Sakai, R. Polycyclic guanidine-containing compounds from the mediterranean sponge Crambe crambe: The structure of 13,14,15-isocrambescidin 800 and the absolute stereochemistry of the pentacyclic guanidine moieties of the crambescidins. J. Org. Chem. 1993, 58, 4805-4808. [CrossRef]

57. Venkateswarlu, Y.; Venkata Rami Reddy, M.; Ramesh, P.; Venkateswara Rao, J. Neofolitispates, pentacyclic guanidine alkaloids from the sponge Neofolitispa dianchora. Indian J. Chem. 1999, 38B, 254-256.

58. Meragelman, K.M.; McKee, T.C.; McMahon, J.B. Monanchorin, a bicyclic alkaloid from the sponge Monanchora ungiculata. J. Nat. Prod. 2004, 67, 1165-1167. [CrossRef] [PubMed]

59. Gallimore, W.A.; Kelly, M.; Scheuer, P.J. Alkaloids from the sponge Monanchora unguifera. J. Nat. Prod. 2005, 68, 1420-1423. [CrossRef] [PubMed]

60. Bensemhoun, J.; Bombarda, I.; Aknin, M.; Vacelet, J.; Gaydou, E.M. Ptilomycalin D, a polycyclic guanidine alkaloid from the marine sponge Monanchora dianchora. J. Nat. Prod. 2007, 70, 2033-2035. [CrossRef] [PubMed]

61. Guzii, A.G.; Makarieva, T.N.; Denisenko, V.A.; Dmitrenok, P.S.; Kuzmich, A.S.; Dyshlovoy, S.A.; Krasokhin, V.B.; Stonik, V.A. Monanchocidin: A new apoptosis-inducing polycyclic guanidine alkaloid from the marine sponge Monanchora pulchra. Org. Lett. 2010, 12, 4292-4295. [CrossRef] [PubMed]

62. Makarieva, T.N.; Tabakmaher, K.M.; Guzii, A.G.; Denisenko, V.A.; Dmitrenok, P.S.; Shubina, L.K.; Kuzmich, A.S.; Lee, H.S.; Stonik, V.A. Monanchocidins B-E: Polycyclic guanidine alkaloids with potent antileukemic activities from the sponge Monanchora pulchra. J. Nat. Prod. 2011, 74, 1952-1958. [CrossRef] [PubMed]

63. Makarieva, T.N.; Tabakmaher, K.M.; Guzii, A.G.; Denisenko, V.A.; Dmitrenok, P.S.; Kuzmich, A.S.; Lee, H.-S.; Stonik, V.A. Monanchomycalins A and B, unusual guanidine alkaloids from the sponge Monanchora pulchra. Tetrahedron Lett. 2012, 53, 4228-4231. [CrossRef]

64. Tabakmakher, K.M.; Denisenko, V.A.; Guzii, A.G.; Dmitrenok, P.S.; Dyshlovoy, S.A.; Lee, H.-S.; Makarieva, T.N. Monanchomycalin C, a new pentacyclic guanidine alkaloid from the far-eastern marine sponge Monanchora pulchra. Nat. Prod. Com. 2013, 8, 1399-1402.

65. Palagiano, E.; De Marino, S.; Minale, L.; Riccio, R.; Zollo, F. Ptilomycalin A, crambescidin 800 and related new highly cytotoxic guanidine alkaloids from the starfishes Fromia monilis and Celerina heffernani. Tetrahedron 1995, 51, 3675-3682. [CrossRef]

66. Patil, A.D.; Kumar, N.V.; Kokke, W.C.; Bean, M.F.; Freyer, A.J.; De Brosse, C.; Mai, S.; Truneh, A.; Faulkner, D.J.; Carte, B.; et al. Novel alkaloids from the sponge Batzella sp.: Inhibitors of HIV gp120-human CD4 binding. J. Org. Chem. 1995, 60, 1182-1188. [CrossRef]

67. Patil, A.D.; Freyer, A.J.; Taylor, P.B.; Carte, B.; Johnson, R.K.; Faulkner, D.J. Batzelladines F-I, novel alkaloids from the sponge Batzella sp.: Inducers of p56 lck_CD4 dissociation. J. Org. Chem. 1997, 62, 1814-1819. [CrossRef]

68. Laville, R.; Thomas, O.P.; Berrue, F.; Marquez, D.; Vacelet, J.; Amade, P. Bioactive guanidine alkaloids from two caribbean marine sponges. J. Nat. Prod. 2009, 72, 1589-1594. [CrossRef] [PubMed]

69. Takishima, S.; Ishiyama, A.; Iwatsuki, M.; Otoguro, K.; Yamada, H.; Omura, S.; Kobayashi, H.; van Soest, R.W.M.; Matsunaga, S. Merobatzelladines A and B, anti-infective tricyclic guanidines from a marine sponge Monanchora sp. Org. Lett. 2009, 11, 2655-2658. [CrossRef] [PubMed]

70. Santos, M.F.; Harper, P.M.; Williams, D.E.; Mesquita, J.T.; Pinto, E.G.; da Costa-Silva, T.A.; Hajdu, E.; Ferreira, A.G.; Santos, R.A.; Murphy, P.J.; et al. Anti-parasitic guanidine and pyrimidine alkaloids from the marine sponge Monanchora arbuscula. J. Nat. Prod. 2015, 78, 1101-1112. [CrossRef] [PubMed]

71. Kornprobst, J.-M. Encyclopedia of Marine Natural Products, 2nd ed.; Wiley-Blackwell: Hoboken, NJ, USA, 2014; Volume 2, pp. 869-877.

72. Daniel Dalet. Planisphère centré Europe Afrique. Available online: http://d-maps.com/carte.php ?num_car=126803\&lang=fr (access on 5 November 2015).

73. Hua, H.-M.; Peng, J.; Dunbar, D.C.; Schinazi, R.F.; de Castro Andrews, A.G.; Cuevas, C.; Garcia-Fernandez, L.F.; Kelly, M.; Hamann, M.T. Batzelladine alkaloids from the caribbean sponge Monanchora unguifera and the significant activities against HIV-1 and AIDS opportunistic infectious pathogens. Tetrahedron 2007, 63, 11179-11188. [CrossRef] 
74. Suna, H.; Aoki, S.; Setiawan, A.; Kobayashi, M. Crambescidin 800, a pentacyclic guanidine alkaloid, protects a mouse hippocampal cell line against glutamate-induced oxidative stress. J. Nat. Med. 2007, 61, 288-295. [CrossRef]

75. Rubiolo, J.A.; Lopez-Alonso, H.; Roel, M.; Vieytes, M.R.; Thomas, O.; Ternon, E.; Vega, F.V.; Botana, L.M. Mechanism of cytotoxic action of crambescidin-816 on human liver-derived tumour cells. Br. J. Pharmacol. 2014, 171, 1655-1667. [CrossRef] [PubMed]

76. Bewley, C.A.; Ray, S.; Cohen, F.; Collins, S.K.; Overman, L.E. Inhibition of HIV-1 envelope-mediated fusion by synthetic batzelladine analogues. J. Nat. Prod. 2004, 67, 1319-1324. [CrossRef] [PubMed]

77. Overman, L.E.; Wolfe, J.P. Synthesis of polycyclic guanidines by cyclocondensation reactions of $\mathrm{N}$-amidinyliminium ions. J. Org. Chem. 2001, 66, 3167-3175. [CrossRef] [PubMed]

78. Rubiolo, J.A.; Ternon, E.; Lopez-Alonso, H.; Thomas, O.P.; Vega, F.V.; Vieytes, M.R.; Botana, L.M. Crambescidin- 816 acts as a fungicidal with more potency than crambescidin- 800 and -830 , inducing cell cycle arrest, increased cell size and apoptosis in Saccharomyces cerevisiae. Mar. Drugs 2013, 11, 4419-4434. [CrossRef] [PubMed]

79. Croue, J.; West, N.J.; Escande, M.L.; Intertaglia, L.; Lebaron, P.; Suzuki, M.T. A single betaproteobacterium dominates the microbial community of the crambescidine-containing sponge Crambe crambe. Sci. Rep. 2013, 3, 2583-2590. [CrossRef] [PubMed]

(C) 2016 by the authors; licensee MDPI, Basel, Switzerland. This article is an open access article distributed under the terms and conditions of the Creative Commons Attribution (CC-BY) license (http://creativecommons.org/licenses/by/4.0/). 